\title{
METÁTESE DE OLEFINAS APLICADA AO FECHAMENTO DE ANÉIS: UMA FERRAMENTA PODEROSA PARA
} A SÍNTESE DE MACROCICLOS NATURAIS

\author{
Anderson Rouge dos Santos e Carlos Roland Kaiser \\ Instituto de Química, Universidade Federal do Rio de Janeiro, Ilha do Fundão, CT, Bloco A, 21941-909 Rio de Janeiro - RJ, \\ Brasil \\ Jean-Pierre Férézou* \\ École Polytechnique, DCSO, UMR CNRS 7652, 91128 Palaiseau cedex, França
}

Recebido em 7/3/07; aceito em 30/8/07; publicado na web em 26/2/08

\begin{abstract}
RING-CLOSING OLEFIN METATHESIS: A POWERFUL TOOL FOR THE SYNTHESIS OF NATURAL MACROCYCLES. For a quarter of a century, metathesis has become indispensable for the synthesis of natural and non-natural products, particularly of biologically active compounds. This review illustrates through a maximum of appropriate examples the power and the versatility of the metathesis ring-closure (RCM) reaction as a key ring-closure methodology for the synthesis of natural macrocycles. Its high functional group compatibility as well as the possibility of further transformations makes this reaction a powerful tool in the cases where the structural framework and function requirements are difficult to meet.
\end{abstract}

Keywords: macrocycles; olefins; ring-closing metathesis.

\section{INTRODUÇÃO}

O advento da reação de metátese de olefinas ("Olefin Metathesis"), como instrumento eficaz para a criação de ligações dupla carbono-carbono, constitui uma verdadeira revolução em síntese orgânica, que foi recompensada em 2005 pela atribuição do Prêmio Nobel de Química aos seus principais inventores Y. Chauvin, R. H. Grubbs e R. R. Schrock ${ }^{1}$. No Brasil, uma revisão já trata das principais aplicações desta reação em síntese orgânica ${ }^{2}$ e alguns grupos de pesquisa estão fortemente envolvidos nesta área, incluindo o desenvolvimento de novos e eficazes catalisadores ${ }^{3}$.

Entre os alvos de escolha para a aplicação desta metodologia os macrociclos estão entre aqueles que recebem uma atenção cada vez maior, em parte devido à grande seletividade da reatividade dos catalisadores e à neutralidade das condições requeridas para efetuar as reações de fechamento de anel, ou RCM ("Ring-Closing Metathesis") $)^{1,4}$.

\section{Os macrociclos naturais}

Quase 40\% de todas os fármacos hoje disponíveis são produtos naturais, ou compostos derivados ou inspirados neles ${ }^{5}$. Entre as moléculas de origem natural, os macrociclos constituem uma classe de metabólitos secundários freqüientemente dotados de atividades biológicas interessantes como, por exemplo, antibióticas, imunossupressoras, anticancerosas, antifúngicas ou inibidoras de enzimas especificas ${ }^{6}$. Em muitos casos, os macrociclos naturais servem como compostos protótipos para o desenvolvimento de fármacos potentes ou, então, apresentam eles mesmos atividades farmacológicas significativas e/ou promissoras para sua utilização como medicamento. A maior parte destas moléculas naturais cíclicas possui núcleos que compreendem entre 12 e 20 membros ${ }^{7}$. Dentre as moléculas possuindo anéis de até 14 membros é observada uma predominância de ciclos carbonados, o que traduz uma origem diterpênica preponderante, enquanto as moléculas com anéis

*e-mail: ferezou@dcso.polytechnique.fr de 16-18 membros contêm de maneira predominante núcleos oxigenados, quase exclusivamente macrolactonas, também conhecidas como macrolidos. A partir de 17 membros, particularmente moléculas de 19 membros, encontra-se uma predominância de macrociclos azotados, sobretudo macrolactamas, traduzindo a presença de ciclopeptídeos e de ciclodepsipeptídeos. Alcalóides macrocíclicos com atividades biológicas múltiplas também estão presentes. Alguns exemplos representativos de macrociclos naturais são apresentados na Figura 1: a epotilona A, macrolido microbiano de 16 membros (anticâncer) ${ }^{8}$; a briostatina I, macrolido de origem marinha com 18 membros (anticâncer) ${ }^{9}$; a apoptolidina, macrolido fúngico de 20 membros (indutor potente de apoptose) $)^{10}$; o jasplaquinolido (jaspamida), ciclodepsipeptídeo de origem marinha com 19 membros (antifúngico, anticâncer) ${ }^{11}$; o ciereszcolido, diterpenóide de 13 membros recentemente isolado de um organismo marinho caribenho ${ }^{12}$.

A importância biológica dos macrociclos naturais, aliada à complexidade desafiadora destes compostos, deu e continua a dar origem a muitos trabalhos de síntese tota ${ }^{13}$. O desenvolvimento de metodologias eficientes para elaborar estes compostos é particularmente crucial no caso de moléculas de acesso difícil, como certos metabólitos de origem marinha ou, ainda, quando se trata de criar análogos estruturais originais com atividade farmacológica otimizada.

Uma etapa estrategicamente decisiva para a síntese dos macrociclos refere-se à formação do núcleo macrocíclico como tal. Tradicionalmente, grande parte dos trabalhos de síntese de heteromacrociclos envolve, nas últimas etapas, a formação da ligação ao nível do heteroátomo, principalmente na síntese total de macrolactonas e macrolactamas. Particularmente no caso dos macrolidos, que compreendem a maioria de moléculas interessantes do ponto de vista farmacológico, várias metodologias de macrolactonização foram desenvolvidas, com destaque para três: a metodologia de Yamaguchi ${ }^{14,15}$, a reação de Steglich ${ }^{16,17}$, ambos os protocolos baseados na ativação do ácido carboxílico, e a metodologia de Mitsunobu ${ }^{18,19}$, baseada na ativação do álcool participante da esterificação seguida de uma reação de substituição $\mathrm{SN}_{2}$. No caso das macrolactamas, as metodologias são semelhan- 


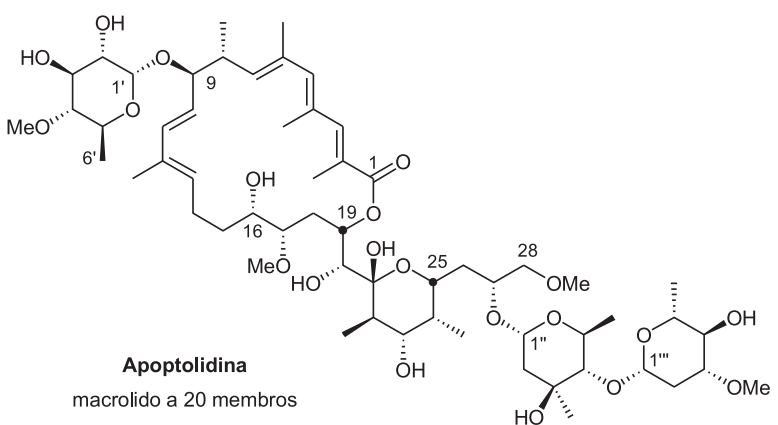

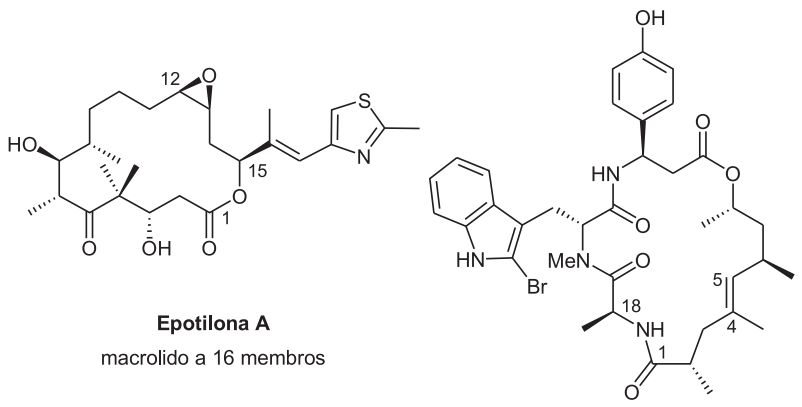

Jasplaquinolido (jaspamido) ciclodepsipeptídeo a 19 membros
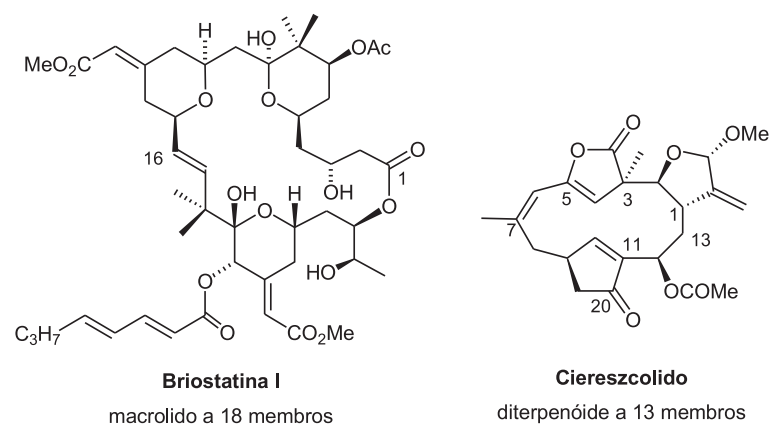

Ciereszcolido
diterpenóide a 13 membros

Figura 1. Alguns exemplos de macrociclos naturais

tes, principalmente com ativação do ácido carboxílico ${ }^{20}$. Entre as limitações observadas, destacam-se os baixos rendimentos obtidos em alguns casos, a necessidade de se trabalhar com algumas funções protegidas, principalmente as hidroxilas existentes em moléculas poliidroxiladas, o que eleva o número de etapas e a necessidade de usar altas diluições para evitar reações de dimerização ou polimerização. Além disso, existe a necessidade de se obter o secoácido durante a etapa de síntese, seja por oxidação de um álcool intermediário ou por saponificação de um éster, cujas condições nem sempre são totalmente compatíveis com os grupos funcionais presentes nos macrociclos mais complexos.

A partir do final dos anos 80 , metodologias de formação de ligação carbono-carbono foram cada vez mais utilizadas em etapas de macrociclização. Dentre estas, destacam-se as reações de formação de ligações duplas, uma estratégia justificada pelo fato de muitos macrociclos naturais conterem ligações duplas isoladas ou conjugadas. Por outro lado, existem vários exemplos de transformações posteriores da ligação dupla endocíclica formada, seja por hidrogenação ou por outros tipos de adição. Dentre as reações mais usadas, podem ser citadas a reação de Horner-Emmons ${ }^{21}$, as rea- ções de acoplamento cruzado intramolecular de Stille ${ }^{22}$, de SuzukiMiyaura $^{23}$ e a reação de acoplamento redutivo de McMurry ${ }^{24}$.

\section{A reação de metátese das olefinas}

O mecanismo da reação de metátese, conhecida desde a década de $50^{25}$, foi proposto em 1971 por Chauvin e Hérisson ${ }^{26}$, que propuseram um metalaciclobutano como espécie intermediaria chave para o rearranjo reversível das olefinas (Esquema 1) ${ }^{2}$.

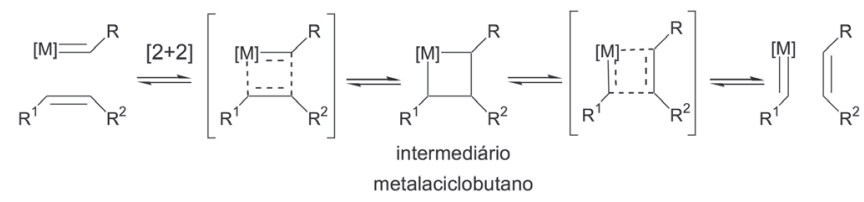

Esquema 1. Macanismo geral para a reação de metátese de olefinas

O advento de complexos estáveis de tipo metal-carbeno permitiu as primeiras aplicações da reação de metátese em síntese orgânica. Hoje, dentre as espécies do tipo metal-carbeno mais usadas para catalisar reações de metátese - na realidade, trata-se formalmente de iniciadores, a partir do momento que o catalisador não é recuperado inalterado no fim da reação - destacam-se o catalisador de molibdênio de Schrock $\mathbf{1}^{27}$, e os catalisadores de rutênio de Grubbs (2-5) estáveis ao ar (Figura 2) ${ }^{28}$. O catalisador de Schrock 1, uma das mais reativas espécies do tipo metal-carbeno, é útil em reações com olefinas deficientes em elétrons e/ou com elevado grau de substituição, permitindo até mesmo a formação de olefinas tetrasubstituídas $^{29}$. Entretanto, a instabilidade deste complexo e a elevada oxofilicidade do centro metálico são dois fatores limitantes a seu uso, principalmente a intolerância a oxigênio e umidade, o que requer condições de atmosfera inerte e rigorosa purificação, secagem e desgaseificação dos solventes e reagentes. Além disso, este catalisador é incompatível com aldeídos e álcoois, sendo necessária proteção dos substratos contendo estes grupos. De um ponto de vista prático, a metátese transformou-se em um procedimento usual de laboratório a partir da comercialização do catalisador de primeira geração de Grubbs-I 3 em 1996 30,31, seguida em 1999 do catalisador mais reativo de segunda geração Grubbs-II $\mathbf{5}^{32}$, obtido a

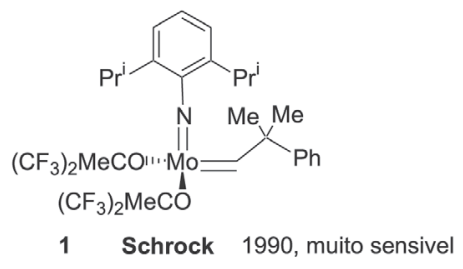

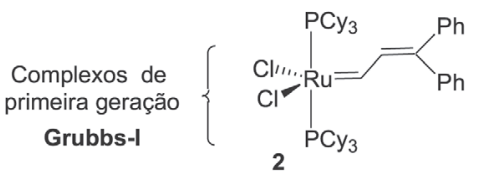

1992

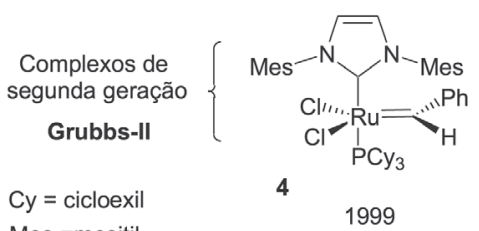

Mes $=$ mesiti

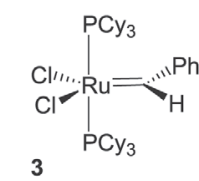

1996, muito usado, comercial
Figura 2. Principais catalisadores empregados em metátese de ofelinas 
partir da troca de um dos ligantes $\mathrm{PCy}_{3}$ por um carbeno $\mathrm{N}$ heterocíclico. A atividade dos catalisadores de Grubbs de primeira geração (Grubbs-I) 2 ou 3 fica limitada frente ao catalisador de Schrock 1, exibindo pouca reatividade com olefinas substituídas. Entretanto, o catalisador de rutênio 3, o mais ativo entre os catalisadores de primeira geração, consegue em alguns casos promover a formação de ligações duplas tri-substituídas ${ }^{30,33}$.

Os catalisadores de rutênio apresentaram-se como alternativa às limitações de estabilidade do catalisador de Schrock 1, devido à elevada tolerância à água, ar, solventes próticos e meio ácido, facilitando os procedimentos experimentais, assim como à grande compatibilidade funcional, em adequação com as necessidades exigidas para a síntese de moléculas complexas. Em geral, o catalisador de Schrock 1 é usado somente nos casos onde o catalisador de Grubbs-II 5 falha.

\section{METÁTESE DE OLEFINAS APLICADA A MACROCICLOS NATURAIS: GENERALIDADES}

\section{O curso da reação}

Entre todas as estratégias desenvolvidas para aplicar a reação de metátese de olefinas em síntese orgânica, uma das mais estudadas e universalmente empregadas envolve a reação de fechamento de anel $(\mathrm{RCM})^{34}$. A estratégia de RCM como etapa chave de formação de anéis vem sendo comumente observada em trabalhos de síntese de compostos macrocíclicos. No Esquema 2 é apresentado o mecanismo simplificado para formação de macrociclos por RCM: o dieno precursor sofre uma cicloadição [2+2] do complexo metalcarbeno $\mathbf{6}$, formando o intermediário metalaciclobutano 7 , que sofre rearranjo e libera etileno no caso de dupla terminal, gerando o complexo metal-carbeno $\omega$-olefínico 8. Por sua vez, este intermediário sofre uma cicloadição [2+2] intramolecular, formando o metalaciclobutano secundário 9 e posteriormente o macrociclo de interesse. Um ponto decisivo para uma boa previsão do andamento desta reação é o aspecto reversível deste processo, que promove competição, devido ao elevado grau de liberdade dos substratos, com a formação de dímeros $\mathbf{1 0}$, geralmente considerados como produtos cinéticos da reação de metátese. A fim de evitar ou, pelo menos, minimizar a formação dos produtos de dimerização e, também, os de oligomerização posterior, geralmente é necessário trabalhar com soluções diluídas, tipicamente inferiores a $10^{-2} \mathrm{~mol} \mathrm{~L}^{-1}$.

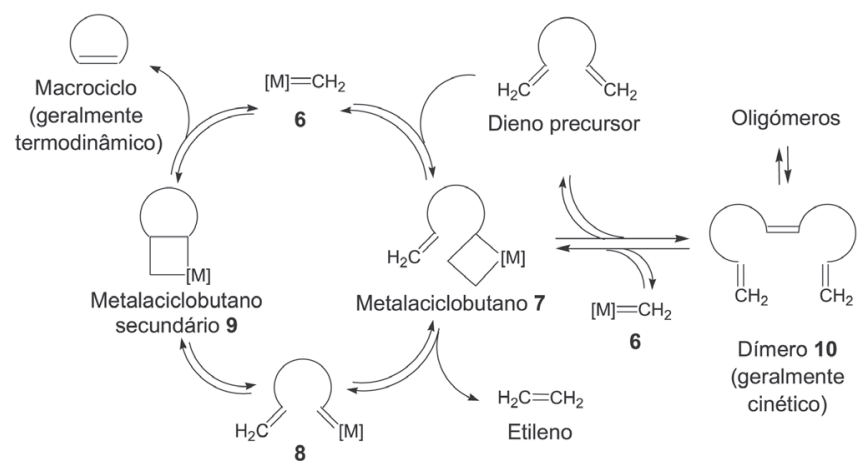

Esquema 2. Mecanismo simplificado de ciclização por reação de matátese de ofelinas (RCM)

Do ponto de vista da reatividade dos substratos, as ligações duplas terminais mono-substituídas mostram-se as mais reativas, sendo observada uma diminuição da reatividade com o aumento da substituição. Contudo, mesmo as ligações dupla tetra-substituídas podem reagir, na presença dos catalisadores mais reativos, como o de Grubbs de segunda geração 5 e, sobretudo, o de Schrock 1.

\section{Produto termodinâmico versus cinético}

Um exemplo que ilustra a influência dos fatores termodinâmicos versus cinéticos na reação de RCM de macrociclos é resumido no Esquema 3. Durante a síntese do anel a 14 membros da fluvirucina $\mathrm{B}_{1}$ por Hoveyda e colaboradores a partir do dieno 11, somente o dímero 12 é formado, resultante do acoplamento cabeça-a-cabeça ("head-to-head") entre as ligações duplas menos substituídas do dieno precursor, em presença do catalisador de Grubbs-I $3^{35}$. Com o catalisador de molibdênio $\mathbf{1}$ mais reativo, o precursor cíclico $\mathbf{1 3}$ da fluvirucina $B_{1}$ é produzido com excelente rendimento e total estereosseletividade $Z$. O interessante é que o tratamento do dímero precedente 12 (o produto cinético da metátese) com 1 fornece também 13 (o produto termodinâmico). Nas etapas finais, a ligação dupla C5-C6 de 13 foi hidrogenada com excelente diastereosseletividade para gerar, após desproteção, a aglicona da fluvirucina $B_{1}(S c h$ 38516) 14.

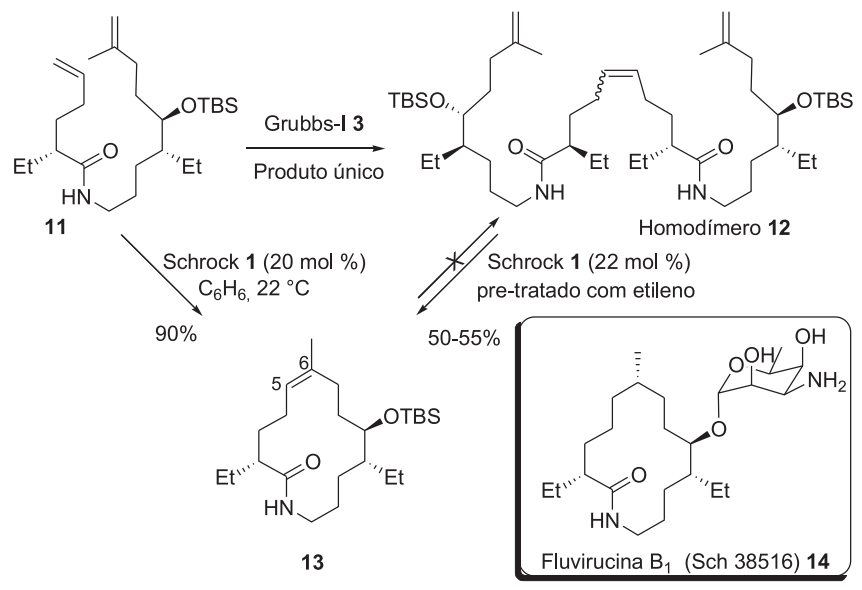

Esquema 3. Aspeto cinético versus termodinâmico: influência do catalisador

\section{Influência das condições experimentais}

Um exemplo descrito por Danishefsky e colaboradores ${ }^{36}$, que evidencia a influência de fatores como a temperatura, o solvente e a concentração para o sucesso das reações de RCM, é o fechamento do macrociclo da epotilona 490 (Figura 5), que envolve o precursor 15, através da reação de uma ligação dupla mono-substituída com um dieno conjugado substituído para gerar o dieno cíclico 16 (Esquema 4). Observou-se que o ganho de temperatura na reação de RCM, aliado com diluição e redução no tempo de reação,

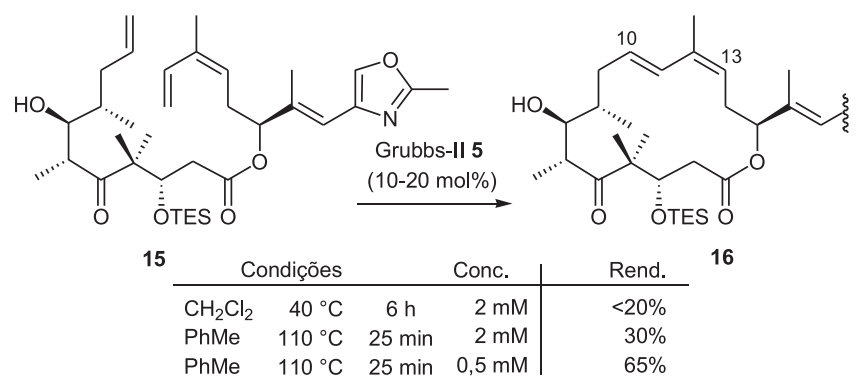

Esquema 4. Epotilona 490: influência do solvente, da temperatura e da concentração sobre a macrociclização por RCM 
permitiu a recuperação de maiores quantidades do macrociclo desejado e evitou a formação de dímeros ou oligômeros.

\section{Papel dos grupos polares}

Observa-se que certas características estruturais presentes nos substratos determinam o curso das reações de RCM. Em estudos pioneiros de fechamento de anéis macrocíclicos por RCM em presença dos catalisadores de rutênio 2 e 3, Fürstner e Langemann mostraram a necessidade da presença de um grupo polar ativante ("relay") no substrato, capaz de reunir as entidades/sítios reativos por quelação, a importância de uma distância adequada entre este grupo polar e o sítio de reação e a influência negativa do impedimento estéreo nas ligações duplas reagentes ${ }^{37}$. Assim, fatores conformacionais favoráveis do substrato diênico, tais como ligações hidrogênio intramoleculares, são determinantes para o resultado final. Contudo, se a quelação das espécies intermediárias for muito estável, a reação pode ter sua evolução impedida. Em estudos sistemáticos de formação de macrolactonas $(\mathbf{1 8}, \mathrm{X}=\mathrm{O})$ e macrolactamas (18, $\mathrm{X}=\mathrm{NH}$ ou NBoc) de 14 membros via $\mathrm{RCM}$, a partir dos dienos 17 em presença do catalisador de rutênio $\mathbf{3}$, Weiler e colaboradores mostraram que a proximidade das ligações dupla a grupos polares (oxigênio da carbonila ou oxigênio/nitrogênio do anel) reduz drasticamente o rendimento da ciclização (Esquema $5)^{38}$.

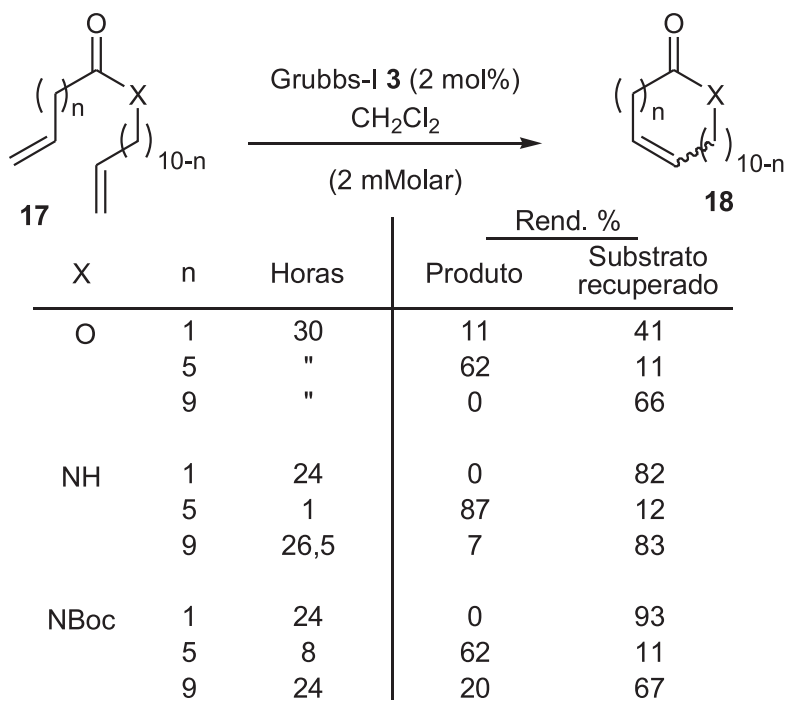

Esquema 5. Formação de lactonas e lactamas macrocíclicas de 14 membros 18 via $R C M$

Estes resultados podem ser interpretados como conseqüência da formação de um complexo inativo do metal com o grupo polar e com a ligação dupla reagente. Em conformidade com as conclusões de Fürstner e Langemann, é possível resumir os casos favoráveis e desfavoráveis segundo a representação mostrada na Figura $3^{39}$.

A fim de desfavorecer a formação de tais quelantes não reativos durante a síntese de macrociclos, os autores recomendam a adição de uma quantidade catalítica de um ácido de Lewis no meio reacional da RCM, geralmente o isopropóxido de titânio (IV) [Ti( $\left.(\mathrm{O} i-\mathrm{Pr})_{4}\right]$. Nestas condições, o ácido de Lewis entra em competição com as espécies rutênio-carbenos pela coordenação com os sítios básicos do substrato, permitindo a formação dos produtos ciclizados. Como exemplos de uso de $\mathrm{Ti}(\mathrm{O} i-\mathrm{Pr})_{4}$, pode ser citada a síntese das moléculas odorantes de estrutura dioxa-macrocíclica $\mathbf{2 0}$ realizada por Eh, onde foi observada a influência negativa da função éter na conversão

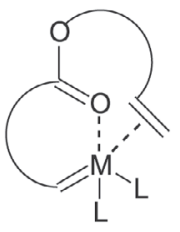

Caso favorável

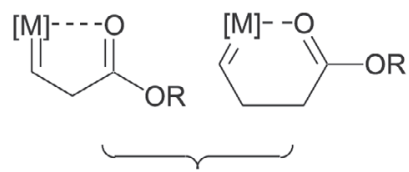

Casos desfavoráveis
Figura 3. Quelações possíveis nos intermediários metal-carbeno em reações de $R C M$

da reação de RCM (Esquema 6) ${ }^{40}$. Os produtos cíclicos 19 só foram obtidos, em excelentes rendimentos, utilizando o catalisador de rutênio 3 em presença de quantidade catalítica de $\mathrm{Ti}(\mathrm{O} i \text { - } \mathrm{Pr})_{4}$.

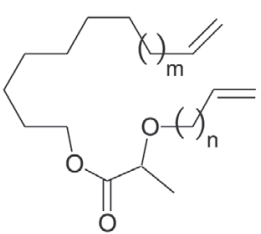

$m, n=1$ ou 2

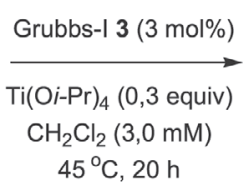

$45^{\circ} \mathrm{C}, 20 \mathrm{~h}$

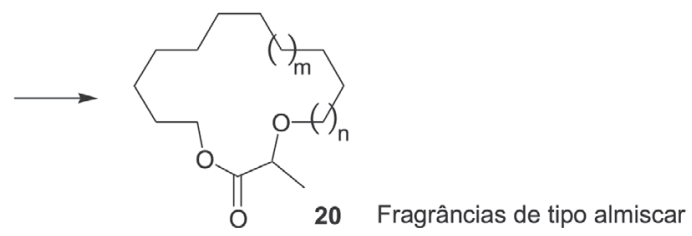

Esquema 6. Fechamento de dioxa-macrociclos via reação de $R C M$ em presença de $\mathrm{Ti}(\mathrm{Oi}-\mathrm{Pr})_{4}$

A formação do macrolido inibidor de germinação (-)-gloeosporona $\mathbf{2 1}^{39}$, assim como da macrolactama 6-nor-fluvirucina $\mathrm{B}_{1} \mathbf{2 2}^{41}$, por RCM em presença de Grubbs-I $\mathbf{3}$ exigiram igualmente a adição de $\mathrm{Ti}(\mathrm{O} i-\mathrm{Pr})_{4}$ no meio reacional (Figura 4).<smiles>CC(C)(C)[C@@H]1CCCCC[C@@H]2CC(=O)[C@](O)(CCC(=O)O2)O1</smiles>

Gloeosporona 21<smiles>[R]C#CCCCCC[C@@H](O)[C@@H](CC)CCCNC(=O)C(CC)CC</smiles>

6-nor-Fluvirucina $B_{1} 22$
Figura 4. Macrociclos preparados via RCM em presença de $\mathrm{Ti}(\mathrm{Oi}-\mathrm{Pr})_{4}$

\section{Quimiosseletividade}

A escolha do bom catalisador para realizar macrociclizações, particularmente nos casos mais complexos, onde várias ligações duplas tendem a competir pela complexação com o metal, pode ser ilustrada pela síntese da unidade macrocíclica central das citotrieninas, lactamas naturais de 21 membros obtidas por fermentação de fungos do gênero Streptomyces, por Panek e colaboradores $(\text { Esquema } 7)^{42}$. Em presença do catalisador de Grubbs-II 5 inicialmente escolhido, o bis-dieno $\mathbf{2 3}$ forneceu o dieno conjugado $\mathbf{2 4}$, 
decorrente da iniciação da reação de RCM a partir de uma das ligações duplas internas do substrato. Com isso, foi necessário utilizar o catalisador menos reativo de Grubbs-I 3, a fim de iniciar a reação por uma das ligações duplas terminais, promovendo a formação do $(E, E, E)$-trieno 25 em bom rendimento e excelente seletividade.

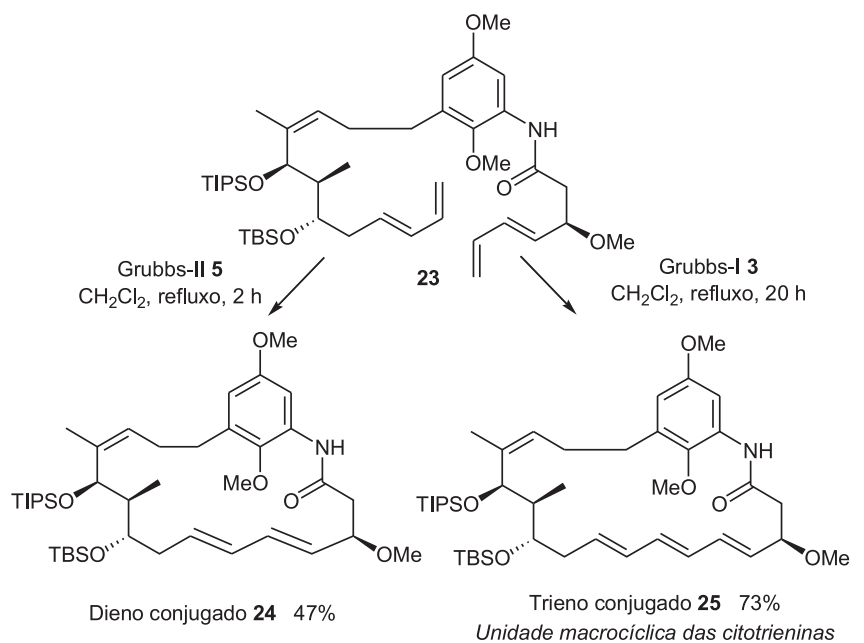

Esquema 7. Síntese da unidade macrocíclica das citotrieninas

\section{Influência da quiralidade}

No caso de moléculas complexas, nem sempre o cumprimento dos parâmetros principais supracitados, necessários para o bom desenvolvimento da reação de RCM, é suficiente para se alcançar a seletividade desejada e com bons rendimentos do macrociclo. Nestes casos, a reação de RCM é muitas vezes dependente de pequenas modificações estruturais no substrato e a sua evolução é de difícil previsão. Desta forma, diferenças aparentemente irrelevantes, como a inversão de um simples estereocentro, podem influenciar o curso da reação. No exemplo tratado por Schreiber e colaboradores e ilustrado no Esquema 8, dois substratos diastereoisoméricos acíclicos 26 e 27, contendo uma cadeia insaturada derivada do mesmo (S)-amino álcool, fornecem produtos cíclicos totalmente diferentes. Quando tratado com o catalisador de Grubbs-II 5, o dieno $\mathbf{2 6}$ fornece o aduto policíclico $\mathbf{2 8}$ contendo um macrociclo de 17 membros, enquanto o diastereoisômero 27 fornece o aduto policíclico fusionado 29, resultado de uma seqüência RCM/ROM/
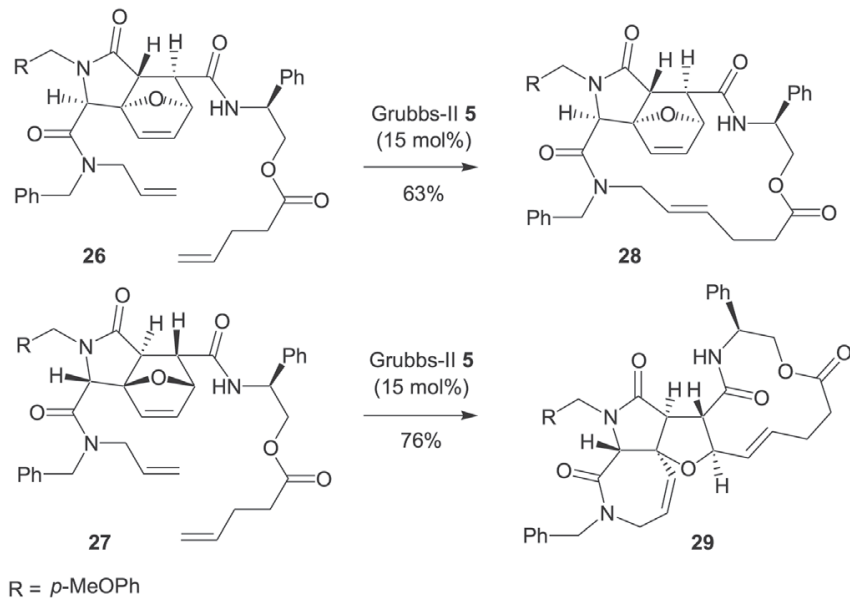

Esquema 8. Influência de um centro quiral sobre o curso da reação de RCM
RCM (ROM = "Ring-Opening Metathesis") formando uma lactama de 7 membros e uma lactona-lactama de 12 membros $^{43}$.

\section{Influência dos grupamentos protetores}

A escolha precisa de grupamentos protetores pode ser decisiva para o sucesso da reação de ciclização, em vários aspectos. No caso da síntese da (+)-aspicilina $\mathbf{3 0}$ por Banwell e McRae, a presença do grupo acetonídeo no precursor diênico 31 prejudica a formação da macrolactona em favor da formação do cicloexeno $\mathbf{3 2}$, que é obtido em rendimento de $81 \%$ em presença do catalisador de Grubbs-I 3 (Esquema 9) ${ }^{44}$. Em contrapartida, quando o diol em C4C5 é protegido na forma do éter sililado 33, a lactona de $18 \mathrm{mem}-$ bros 34 é obtida em bom rendimento. Um problema similar foi observado por Ley e colaboradores durante a síntese da mesma molécula: o tratamento do intermediário chave, o trieno quiral 35, com o catalisador de Grubbs-I 3 forneceu o macrociclo desejado em rendimento de $76 \%$, juntamente com o cicloexeno correspondente em rendimento de $26 \%$.<smiles>C=CCCCCCCCC(C)OC(=O)C=C[C@H]1OC(C)(C)O[C@@H]1C</smiles><smiles>C=CCCCCCCCC(C)OC(=O)/C=C/C(O)C(O)CC=C</smiles>

33<smiles>CC#CCCCCCCCCC(O)C(O)C(O)C=CC(=O)OC(C)CCCC</smiles>

(+)-Aspicilina 30

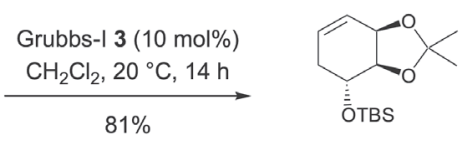

32

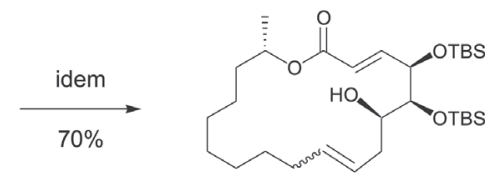

$34(E / Z 3: 1)$

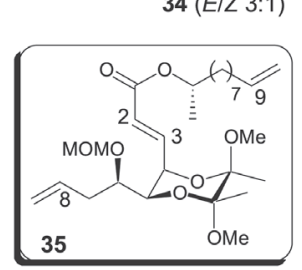

Esquema 9. Etapas de RCM na síntese da (+)-aspicilina

\section{Estereosseletividade}

Além das múltiplas vantagens destacadas acima, a formação de macrociclos por RCM apresenta certas particularidades que necessitam de alguns comentários. Uma dificuldade para aplicação da reação de RCM em síntese é o controle da estereosseletividade da ligação dupla criada, sendo obtidas, freqüentemente, misturas de isômeros $E$ e $Z$. Vários fatores podem influenciar a estereosseletividade obtida.

\section{Produto termodinâmico versus cinético}

É importante relembrar que a formação dos produtos macrocíclicos, via reação de RCM, geralmente ocorre sob controle termodinâmico. Contudo, em certos casos o catalisador não é ativo suficientemente para equilibrar os produtos cinéticos da reação, o que pode resultar na produção do isômero menos estável ${ }^{4}$. Estes aspectos foram ilustrados por Lee e Grubbs ${ }^{46}$, em estudos sistemáticos de fechamento do dieno $\mathbf{3 6}$ em presença dos catalisadores de Grubbs-I 3 e Grubbs-II 5 (Esquema 10). Foi observada uma aparente independência entre a razão $E / Z$ da ligação dupla formada, presente na lactona de 14 membros 37 e o substrato utilizado (en- 
tradas 1 e 5). Esses autores também estudaram a variação da razão $E / Z$ em função do tempo e do catalisador utilizado. Em presença do catalisador 5, a razão $E / Z$ aumentou com o tempo, até alcançar o equilibro termodinâmico, o que não aconteceu com o uso do catalisador 3, menos reativo. Um estudo mais recente sobre o problema do controle da estereosseletividade $E / Z$ foi publicado, tratando do caso dos macrolidos marinhos salicilialamidas (Figura 6), resultando nas mesmas conclusões ${ }^{47}$.<smiles>[R]C=CCOC(=O)CC=C</smiles>

36

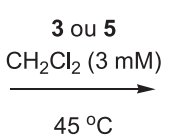

$45^{\circ} \mathrm{C}$

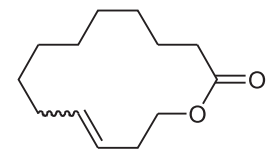

37

\begin{tabular}{ccccl|rr} 
Entrada & $\mathrm{R}$ & \multicolumn{2}{c|}{ Cat. $(\mathrm{mol} \%)$} & Tempo & $\begin{array}{r}\text { Rend. } \\
(\%)\end{array}$ & $E / Z$ \\
\hline 1 & $\mathrm{H}$ & $\mathbf{5}$ & $(1,0)$ & $40 \mathrm{~min}$ & 100 & $11,5: 1$ \\
2 & $"$ & $\mathbf{3}$ & $(5,0)$ & $5,0 \mathrm{~h}$ & 97 & $4,5: 1$ \\
3 & $\mathrm{Et}(\mathrm{Z})$ & $\mathbf{5}$ & $(0,5)$ & $30 \mathrm{~min}$ & 100 & $9,7: 1$ \\
4 & $"$ & $\mathbf{3}$ & $(5,0)$ & $6,5 \mathrm{~h}$ & 77 & $4,5: 1$ \\
5 & $\left(\mathrm{CH}_{2}\right)_{4} \mathrm{Me}(\mathrm{Z}) \mathbf{5}$ & $(0,5)$ & $40 \mathrm{~min}$ & 100 & $10,8: 1$ \\
6 & $\mathrm{CH}_{2} \mathrm{OAc}(E)$ & $\mathbf{1}$ & $(2,0)$ & $3,0 \mathrm{~h}$ & 80 & $9,7: 1$
\end{tabular}

Esquema 10. Macrolactonas de 14 membros: Estereosseletividade da reação de $R C M$

\section{Escolha do catalisador}

A seleção apropriada do catalisador pode, em alguns casos, conduzir seletivamente ao produto termodinâmico ou cinético da metátese. No caso das lactonas de anel médio herbaruminas I $42 \mathrm{e}$ II 43 sintetizadas por Fürstner e colaboradores, o produto de ciclização mais estável é o isômero Z-40, não natural (Esquema $11)^{48}$. Este último é obtido de maneira exclusiva a partir do dieno 38, em presença do catalisador mais reativo Grubbs-II 4 que fornece o produto termodinâmico. Em contrapartida, o catalisador 39, cuja reatividade se assemelha à dos catalisadores menos reativos de Grubbs de primeira geração, fornece de maneira preponderante o isômero cinético $E-41(\mathrm{R}=\mathrm{H}, E / Z=7.7: 1)$. No caso da herbarumina II 43 que possui uma hidroxila protegida em $\alpha$ à carboxila, o isômero $E$ é obtido de maneira exclusiva.

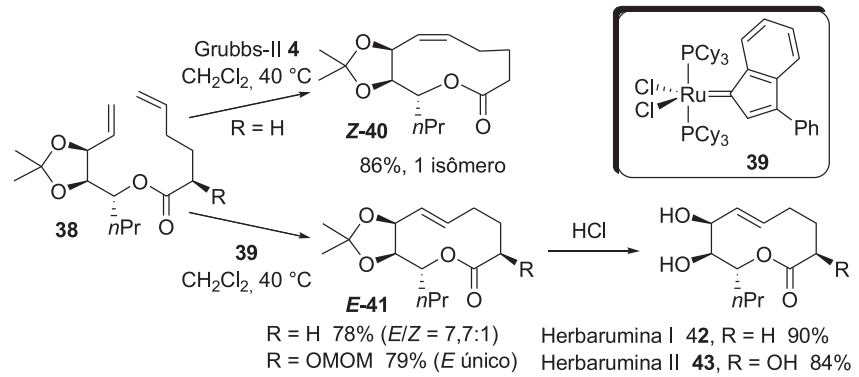

Esquema 11. Herbaruminas: influência do catalizador sobre a seletividade $E / Z$

Uma observação semelhante foi feita por Marco e colaboradores na síntese do microcarpolido 45 (Esquema 12), onde o isômero natural de configuração $E$, o produto cinético da reação de RCM, é obtido de maneira majoritária a partir do acetonídeo 44 usando o catalisador de Grubbs-I 3 (com o catalisador de Grubbs-II 5, só o isômero $\mathrm{Z}$ é formado) ${ }^{49}$.

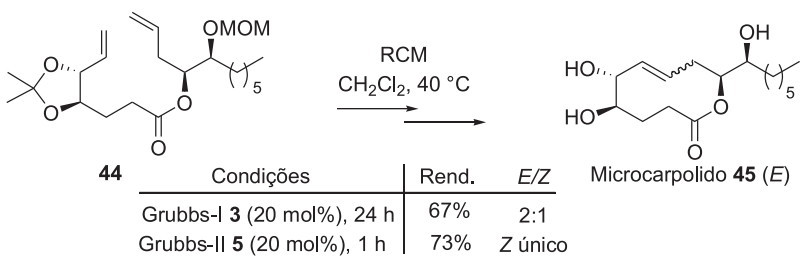

Esquema 12. Microcarpolido: influência do catalisador sobre a seletividade $E / Z$

Influência dos substituintes e dos grupos protetores

O exemplo da tonantzitlolona ilustra a importância dos substituintes e dos grupos protetores sobre o curso da reação de metátese para alvos moleculares altamente substituídos. Kirschning e colaboradores empreenderam a síntese enantiosseletiva deste diterpeno macrocíclico natural de 15 membros, isolado da planta mexicana Stillingia sanguinolenta, com uma ambição dupla: realizar a primeira síntese total deste macrociclo complexo e estabelecer a configuração absoluta, ainda não determinada ${ }^{50}$. Numa primeira abordagem, os autores testaram o fechamento ao nível da ligação dupla C1-C2, aparentemente o mais lógico. A reação de macrociclização por RCM e também a reação de McMurry falharam, devido provavelmente ao impedimento estéreo dos três grupos metila em posição alílica. Desta forma, foi elaborada a rota alternativa de fechamento do macrociclo ao nível da ligação C4-C5, o que necessitou de uma reação posterior de diidroxilação da ligação dupla formada, necessária na formação do sistema $\alpha$-ceto-pirânico da tonantzitlolona (Esquema 13). Submetido à reação de RCM em presença do catalisador de Grubbs-II 5, o triol 1,3-bis-protegido na forma de acetonídeo 47 , preparado a partir do intermediário chave 46, forneceu o macrociclo $\mathbf{4 8}$ com elevada estereosseletividade para o isômero Z. Dificuldades encontradas na etapa posterior, a
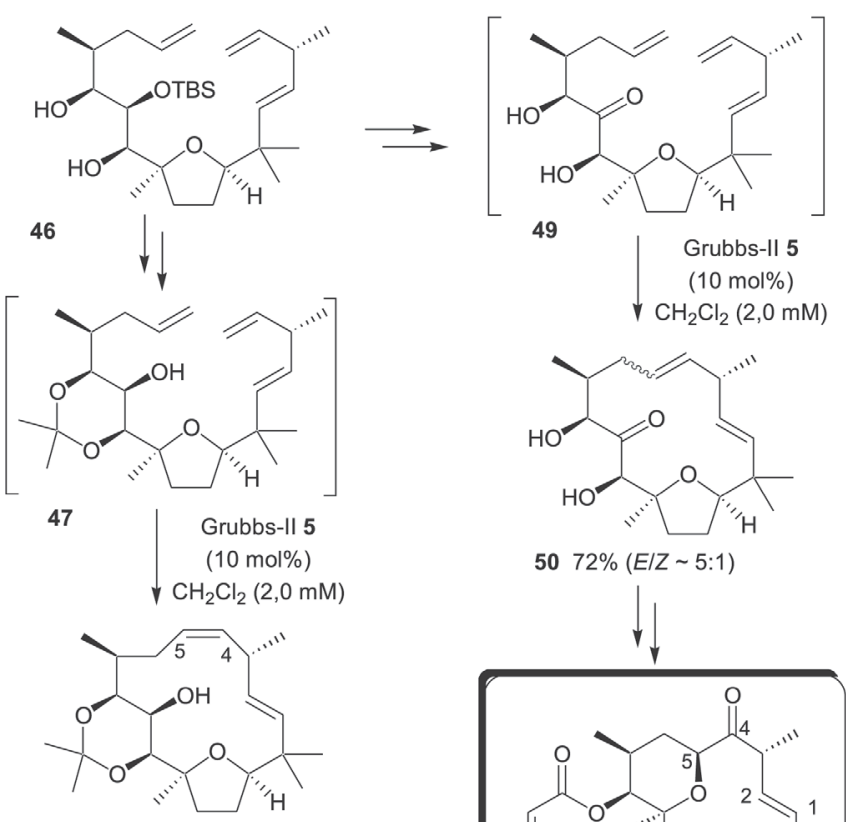

$4870 \%(Z / E \sim 6: 1)$
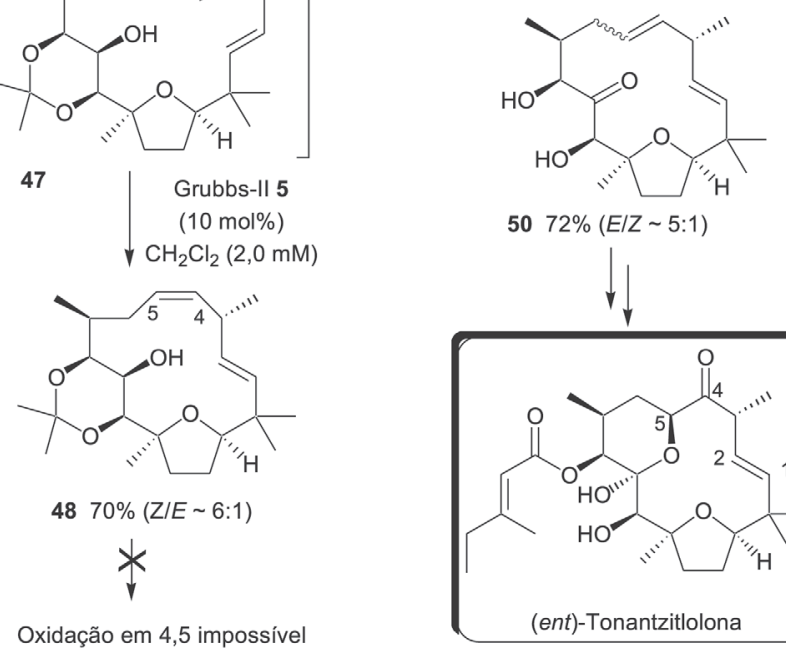

$5072 \%(E / Z \sim 5: 1)$

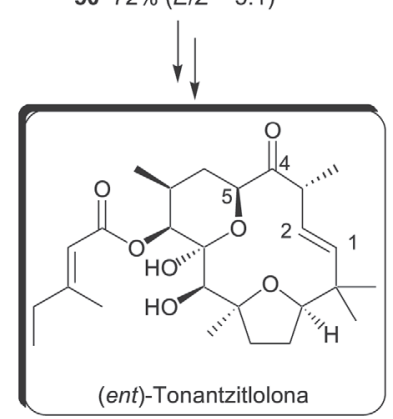


diidroxilação da ligação dupla, levaram os autores a tentar a reação com a diidroxicetona 49, gerando o macrociclo $\mathbf{5 0}$ com boa seletividade para o isômero $E$ desejado. Este intermediário foi posteriormente transformado no composto $(e n t)$-tonantzitlolona $\left([\alpha]_{D}\right.$ $=-119)$, enantiômero do produto natural $\left([\alpha]_{\mathrm{D}}=+134\right)$.

Desde os primeiros trabalhos pioneiros dos grupos de Nicolaou e colaboradores $^{51}$ e de Danishefsky e colaboradores ${ }^{52}$, em 1997, a família das epotilonas (Figura 5) foi certamente objeto do maior número de estudos sintéticos utilizando como etapa chave a reação de RCM, estimulados pelas atividades anticancerígenas notáveis destas moléculas. O âmbito destes estudos tem sido amplamente relatado ${ }^{4,53}$.

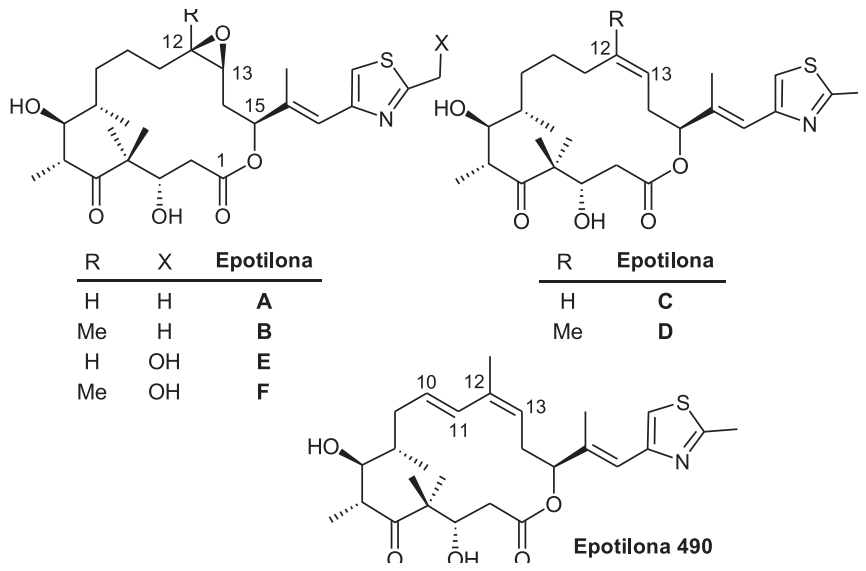

Figura 5. Estrutura das epotilonas, macrolidos antitumorais de 16 membros

Um ponto de escolha "natural" para o fechamento do anel de 16 membros destas moléculas é a formação da ligação dupla C12-C13. A obtenção das epotilonas A, B, E e F também se torna viável através da ligação dupla de configuração $Z$, sendo necessária uma oxidação posterior para gerar a função epóxido. O controle da configuração da ligação dupla mostrou-se um problema muito delicado a ser resolvido e a reação de RCM, em presença dos catalisadores de Grubbs-I 3 ou de Schrock 1, só conduziu a misturas de isômeros $E$ e $Z$ em várias proporções, dependendo dos substituintes já presentes no dieno precursor e dos grupos protetores utilizados. Mais recentemente, a fim de contornar o problema da falta de estereosseletividade na instalação da ligação dupla $\mathrm{C} 12-\mathrm{C} 13$, outras abordagens foram desenvolvidas implicando, por exemplo, no fechamento do anel em C10-C11. De maneira geral, modificações estruturais ou funcionais, mesmo distantes do sítio ativo, podem promover mudanças significativas na estereosseletividade observada ${ }^{54}$. Assim, duas outras estratégias alternativas permitiram contornar o problema da estereosseletividade com sucesso, entre elas, a criação de junção do anel ao nível da ligação simples C9-C10 (Esquema 14). Depois de insucessos iniciais com os catalisadores de Schrock $\mathbf{1}$ e de Grubbs-I 3 e devido

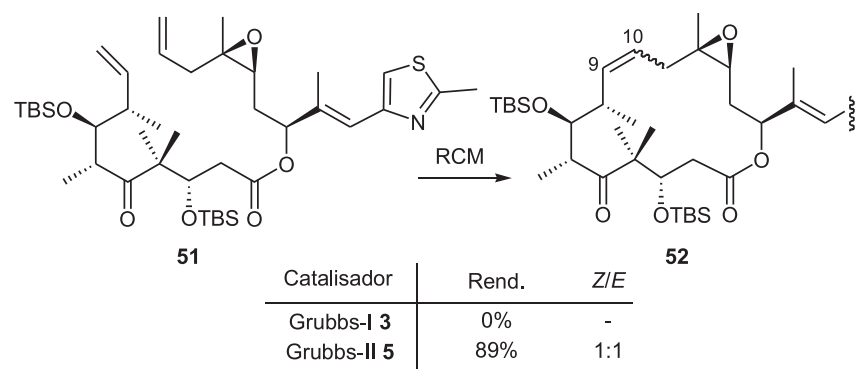

Esquema 14. Fechamento do macrociclo das epotilonas em C9-C10 ao grande impedimento estéreo dos substituintes na vizinhança do sítio da reação no substrato $\mathbf{5 1 ^ { 5 2 }}$, somente o uso do catalisador de Grubbs-II 5, por Sun e Sinha, permitiu concretizar esta abordagem, produzindo o macrolido $52(\mathrm{R}=\mathrm{Me})$ em $89 \%$ de rendimento ${ }^{55}$. A mistura 1:1 de isômeros $Z / E$ foi posteriormente hidrogenada e transformada em epotilona $B$.

O problema da falta de estereosseletividade na formação da ligação dupla final do macrociclo pode também ser contornado de maneira indireta, pelo uso de uma reação de fechamento de anel por metátese de alcinos ("Ring-Closing Alkyne Metathesis" ou RCAM), desenvolvida por Fürstner e Davies, onde a ciclização é efetuada a partir de um diino, em vez de um dieno, o que resulta na obtenção de um macrociclo contendo uma tripla ligação $0^{56}$. No caso do diino $\mathbf{5 3}$, o alcino cíclico $\mathbf{5 4}$ foi obtido em rendimento de $80 \%$ em presença de complexo de molibdênio $\mathbf{5 6}$ (Esquema 15) (5) $^{57}$ As reações posteriores de hidrogenação parcial ( $\mathrm{H}_{2} /$ catalisador de Lindlar / quinolina) e de desproteção final forneceram, em bom rendimento, a epotilona C 55 de configuração exclusiva $Z$ da ligação dupla C12-C13.

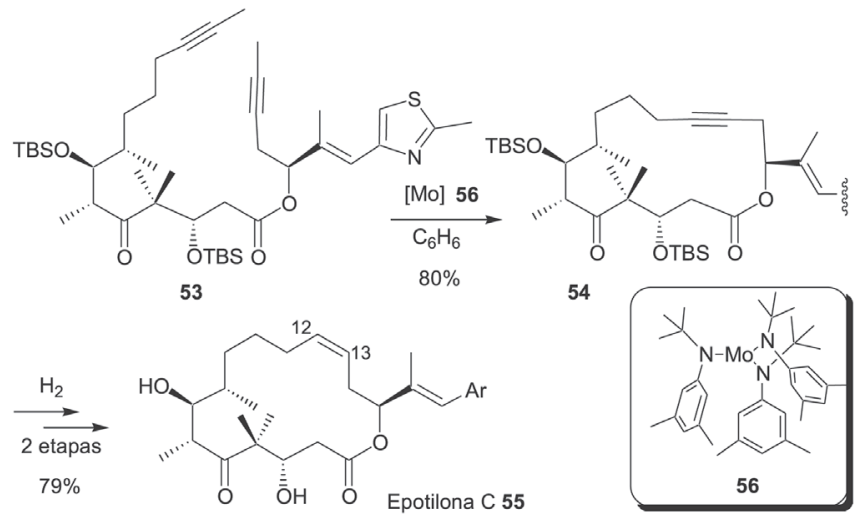

Esquema 15. Fechamento do macrociclo das epotilonas por metátese de alcinos

\section{EXEMPLOS DE METÁTESE DE OLEFINAS APLICADA À SÍNTESE TOTAL DE MACROCICLOS NATURAIS}

Neste capítulo são descritos alguns exemplos representativos de aplicação de catalisadores de tipo metal-carbeno em síntese de produtos naturais. Não são abordadas aqui, de maneira específica, as aplicações que envolvem ligações triplas na ciclização (reações do tipo enyne-RCM e RCAM) ou combinações estratégicas mais complexas envolvendo cascata de reações como CM/RCM, ROM/ $\mathrm{RCM}, \mathrm{RCM} / \mathrm{ROM} / \mathrm{RCM}^{2}$.

Os catalisadores de Grubbs-I foram compostos de escolha em muitos trabalhos de síntese de macrociclos, principalmente o catalisador de rutênio 3. Já o catalisador de Schrock 1 mostrou aplicação nos sistemas onde os catalisadores de Grubbs-I não atuavam ou atuavam de maneira pouco eficiente. Ainda hoje, os catalisadores de rutênio de primeira geração têm grande aplicação em sistemas mais simples.

\section{Salicilialamidas/oximidinas}

As enamidas salicílicas (Figura 6) são macrolactonas de 12 membros de origem marinha possuindo atividades antitumorais notáveis, com um novo mecanismo de ação envolvendo V-ATPases como alvos moleculares ${ }^{58}$.

As atividades farmacológicas promissoras destas famílias de moléculas estimularam numerosos trabalhos de síntese que foram 


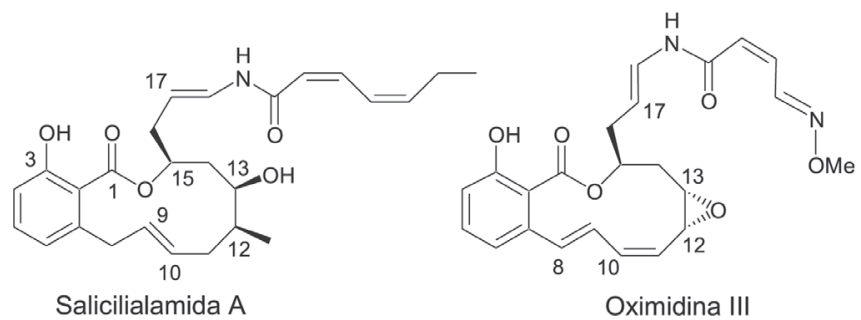

Figura 6. Estrutura de dois enamidas salicílicas

objeto de uma revisão por Yet, em $2003^{59}$. Um grande número de estratégias de síntese adotadas implicou em uma reação de RCM ao nível dos centros C9-C10 para gerar a macrolactona. A influência da natureza do substituinte em posição $\mathrm{C} 15$, assim como dos grupos protetores das hidroxilas fenólica $\mathrm{OH}-3$ e secundária $\mathrm{OH}-$ 13, sobre o rendimento e a configuração da ligação obtida foi amplamente investigada no caso das salicilialamidas. De maneira geral, o catalisador de Grubbs-I 3 fornece a melhor proporção de isômero $E$ desejado. Provavelmente o produto cinético da reação, como ilustrado na síntese recentemente realizada por Maier e colaboradores, onde a ciclização do dieno precursor 57 em presença de $\mathbf{3}$ produz o macrociclo $\mathbf{5 8}$ com melhor seletividade $E$ (Esquema $16)^{60}$.

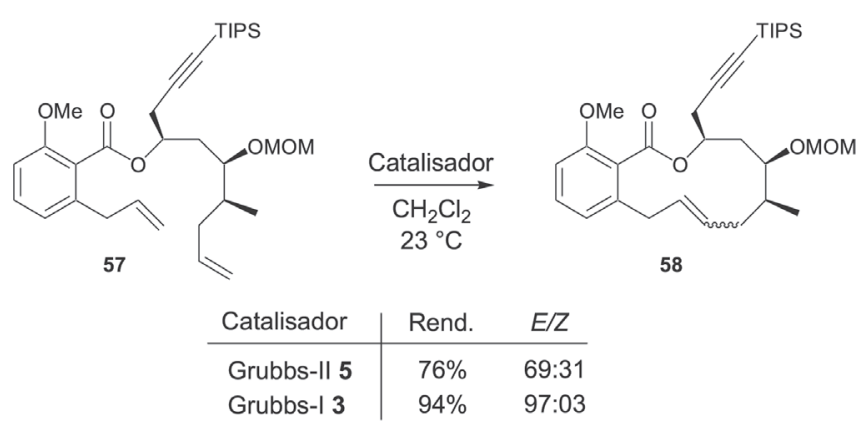

Esquema 16. Influência do catalisador

A forte dependência da estereosseletividade da reação de fechamento de anéis em função da proteção ao nível da hidroxila fenólica $\mathrm{OH}-13$ foi demonstrada por Georg e colaboradores, usando o catalisador de Grubbs-I 3 (Esquema 17) ${ }^{61}$. Na presença da hidroxila fenólica livre, o macrociclo de 12 membros $\mathbf{6 0}$ com a ligação dupla $Z$ é obtido como produto majoritário a partir do dieno $\mathbf{5 9}(\mathrm{R}=\mathrm{H})$. Este resultado pode ser devido à existência de uma conformação desfavorável do dieno precursor decorrente, por exemplo, da existência de uma ligação hidrogênio entre a hidroxila e a carboxila vizinha.

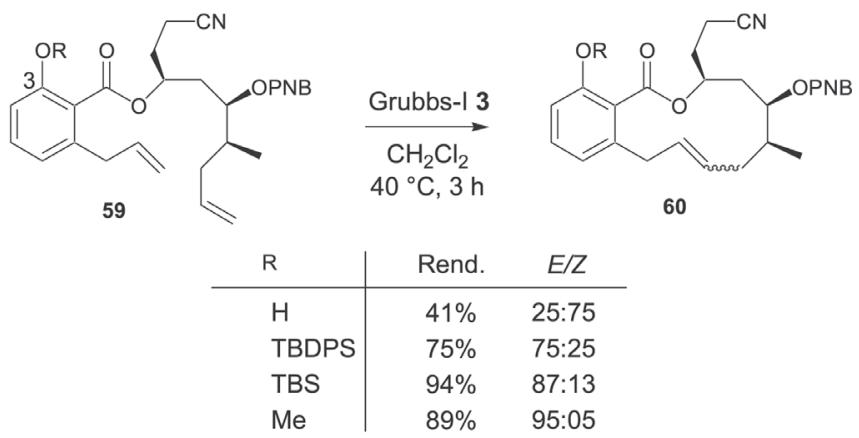

Esquema 17. Influência da proteção da hidroxila fenólica
Em certas situações, um problema encontrado no fechamento de anéis por metátese envolve a necessidade de se utilizar de artifícios para forçar o dieno precursor a reagir de um lado preferencial, ou seja, induzir a formação do intermediário metal-carbeno mais produtivo, evitando a formação de intermediários não-reativos ou que levem à formação de subprodutos. Varias soluções foram testadas para contornar estas dificuldades, tais como o bloqueio da extremidade improdutiva e a ativação intermediária ("relay") da extremidade desejada ${ }^{62}$.

Exemplos destas abordagens foram descritos por Wang e Porco, durante a síntese de oximidina II 64 (Esquema 18). Os autores observaram que o uso do substrato 61a, contendo um dieno $E$ e um dieno $Z$ terminais, não conduziu a produtos de ciclização quando tratados com catalisadores de Grubbs-I ou II. Apenas os produtos resultantes da reação do dieno $E$ com os catalisadores foram obtidos, assim como o complexo conjugado pouco reativo $\mathbf{6 2}^{63}$. Conseqüentemente, a reatividade do dieno $E$ foi reduzida por incorporação de um grupo metila (dieno 61b), favorecendo a iniciação da reação a partir do dieno $Z$, o que resultou, após tratamento com o catalisador de Grubbs-II 5, na macrolactona $63 \mathrm{em} 48 \%$ de rendimento.

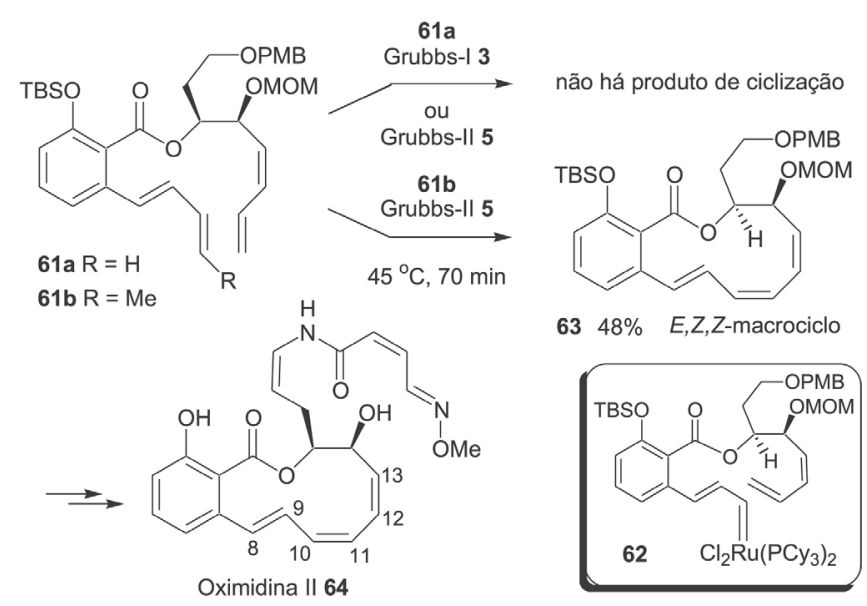

Esquema 18. Síntese da oximidina II via RCM

Posteriormente, os mesmos autores efetuaram a síntese da oximidina III 68, substância contendo um epóxido na posição C12C13 (Esquema 19) ${ }^{64}$. Desta vez, além da desativação do dieno $E$ pela introdução de um grupo metila, como feita anteriormente, Wang e Porco utilizaram uma abordagem "relay", introduzindo do lado do epóxido alílico uma cadeia contendo uma ligação dupla terminal reativa (65b). Na presença do catalisador de Grubbs-II 5, o

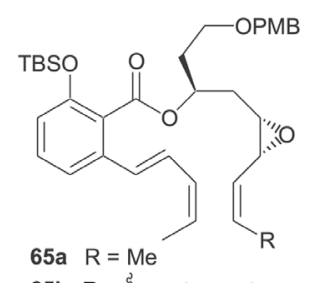<smiles>CCCC1C=CCC1</smiles><smiles>C/C=C\C=C/c1cccc(OC(C)C)c1C(=O)OC(CCOCC)CCOCC</smiles><smiles>[R]C(C)(C)CCCCC=C</smiles>

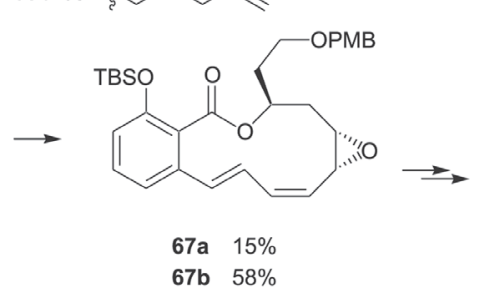<smiles>C/C=C\C=C/c1cccc(O)c1C(=O)OC(C/C=C/NC(=O)/C=C\C=N\OC)CC1CO1</smiles>

Oximidina III 68

Esquema 19. Síntese da oximidina III via uma estratégia "relay" 
intermediário $\mathbf{6 5 b}$ forneceu o produto de ciclização esperado $\mathbf{6 7 b}$ com rendimento de $58 \%$, via uma dupla reação de RCM, com formação intermediária da espécie metal-alquilideno 66 e liberação de ciclopenteno. Na ausência da ativação intermediária, o substrato 65a forneceu 67a com um rendimento de apenas $15 \%$.

\section{Análogos de mixovirescina}

A síntese de análogos simplificados do antibiótico mixovirescina A1 foi efetuada por Dutton e colaboradores, a fim de estudar correlações estrutura-atividade ${ }^{65}$. Neste trabalho, a reação de RCM foi utilizada para construir um anel de 28 membros, sendo o análogo 70 obtido em presença do catalisador mais reativo de Schrock 1, devido à presença no substrato 69 de uma olefina terminal di-substituída, para gerar um macrociclo com olefina tri-substituída (Esquema 20). Já na ciclização do substrato 71 entre duas olefinas terminais mono-substituídas, o catalisador de Grubbs-I 3 foi o iniciador de escolha, gerando o macrociclo 72 de configuração $E$ em $90 \%$ de rendimento. O uso de Grubbs-I 3 permitiu a presença de um grupo hidroxila desprotegido em 71, o que não é possível com o catalisador mais instável de Schrock $\mathbf{1}$.

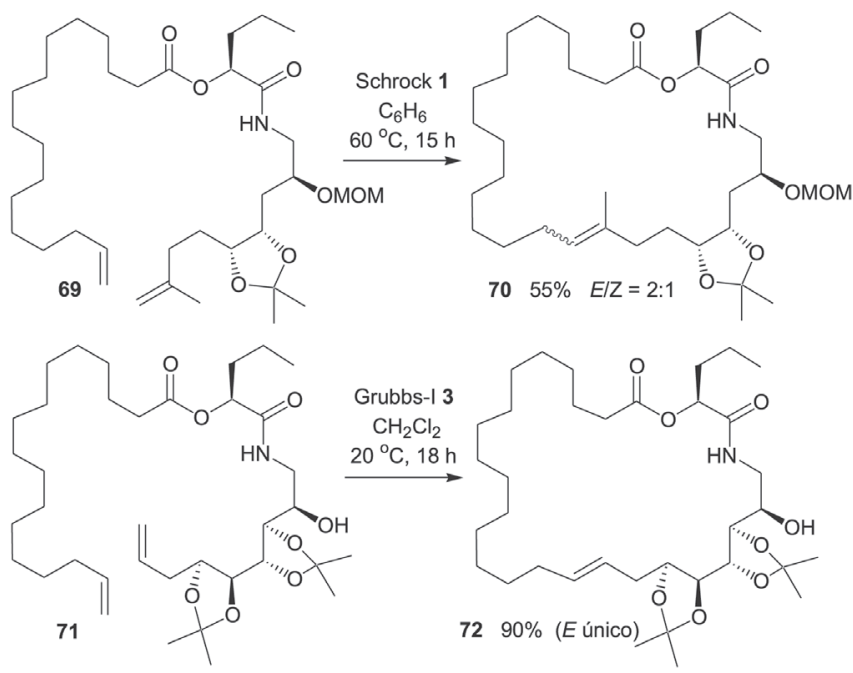

Esquema 20. Síntese de análogos da mixovirescina via RCM

\section{Geldanamicina}

Lemarchand e Bach desenvolveram a síntese de um modelo do antibiótico geldanamicina, uma para-quinona macrolactâmica de 19 membros obtida de fungos do gênero Streptomyces ${ }^{66}$. Os autores prepararam os intermediários 72-74, que foram submetidos à etapa de RCM em presença do catalisador de Grubbs-I 3, para formar as ansamacrolactamas 75 (Esquema 21). No trabalho preliminar de otimização a partir dos precursores $\mathbf{7 2}(\mathrm{n}=1$ a 5), estes autores observaram que a formação das macrolactamas de 16 e 17 membros $75(n=1$ e 2) não foi possível, devido à tensão no anel macrolactâmico promovida pelo anel aromático ${ }^{67}$. A ligação dupla formada nos compostos diênicos $\mathbf{7 5}$ com $n>2$ apresentou uma configuração $Z$, em conformidade com a configuração do produto natural. O mesmo não aconteceu no caso do substrato desconjugado 73, que forneceu uma mistura inseparável de diastereoisômeros $Z$ e $E$. Devido à dificuldade de desproteção, os compostos com $\mathrm{R}=$ Me se mostraram inadequados para a continuação da síntese, sendo então o intermediário 74 (contendo o grupo lábil $\mathrm{R}=i$ Pr), testado, o que resultou no produto cíclico de interesse com $87 \%$ de rendimento e estereosseletividade exclusiva $Z$.

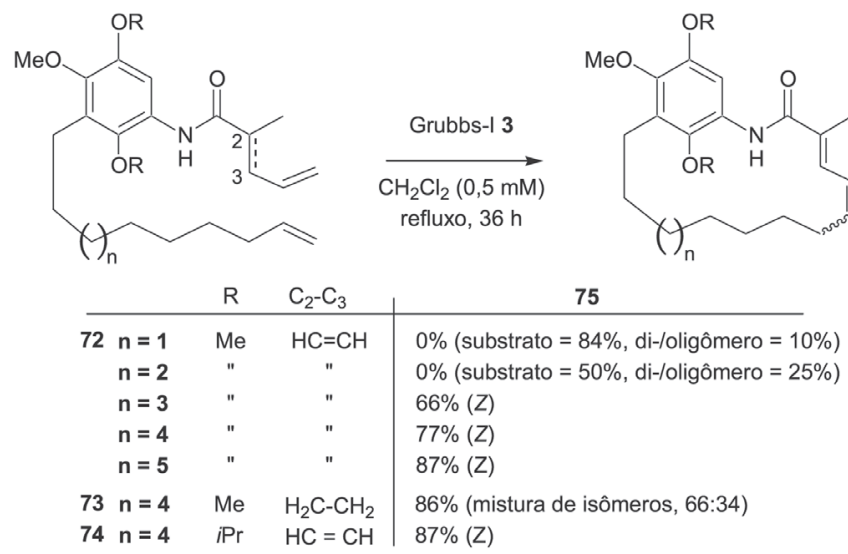

Esquema 21. Análogos simplificados da geldanamicina via RCM

\section{Muscona}

Numerosas aplicações da reação de RCM referem-se à formação de produtos intermediários, onde a ligação dupla criada durante a ciclização é posteriormente transformada. A reação de RCM foi utilizada por Hagiwara e colaboradores em 1998, em uma rota simples de síntese da cetona cíclica de 15 membros $(R)$-(-)-muscona 78 (Esquema 22) ${ }^{68}$. O dieno intermediário 76a $(\mathrm{R}=\mathrm{Me}$ ) foi preparado facilmente a partir do $(R)$-(+)-citronelal comercial e do 1bromo-9-deceno, seguido de oxidação do álcool secundário formado e RCM em presença do catalisador de Grubbs-I 3. Como este catalisador não possui grande eficiência com ligação dupla tri-substituída, somente o dímero do substrato foi observado (formado a partir da ligação dupla terminal). Em presença do mesmo catalisador, o dieno menos substituído 76b, preparado por ozonólise de 76a seguida de reação de Wittig, conduziu à cetona de 15 membros $\mathbf{7 7 b}$ em rendimento de $78 \%$ e baixa estereosseletividade. Posterior hidrogenação da mistura forneceu a $(R)-(-)$-muscona $\mathbf{7 8}$.

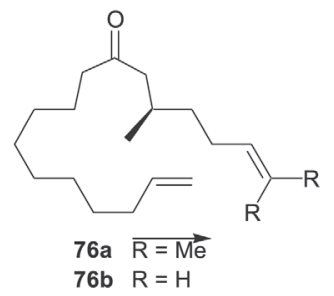

$\mathrm{H}_{2}, 10 \% \mathrm{Pd} / \mathrm{C}$

$\mathrm{EtOH}, 98 \%$
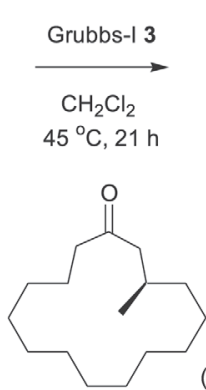

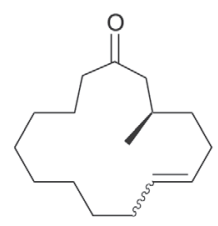

77 a $0 \%$ (dímero: $83 \%$ )

77b $78 \%$ (mistura $E / Z$ )
(R)-(-)-Muscona 78

Esquema 22. Síntese de (R)-(-)-muscona, ref. 68

Mais recentemente, Grubbs e colaboradores publicaram uma síntese alternativa da mesma $(R)$-(-)-muscona 78 a partir do álcool 79, através de um elegante processo em uma etapa ("one pot") envolvendo três reações seqüenciais (RCM - desidrogenação por transferência de $\mathrm{H}$ - hidrogenação) mediadas pelo mesmo complexo de rutênio, o catalisador de Grubbs de segunda geração 5 (Esquema 23$)^{69}$. O rendimento deste processo de catálise em cascata ("tandem") foi de $56 \%$ e, como esperado, mostrou-se melhor a partir da cetona 76a (75\%). Os autores postulam que o hidretocomplexo $\mathrm{RuHCl}\left(\mathrm{H}_{2}\right)\left(\mathrm{PCy}_{3}\right)_{2}$, obtido em presença de hidrogênio, seja o catalisador efetivo da hidrogenação. 

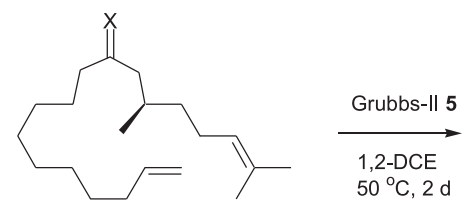

$79 \quad \mathrm{X}=\mathrm{H}, \mathrm{OH}$ (mistura) 76a $\quad X=0$

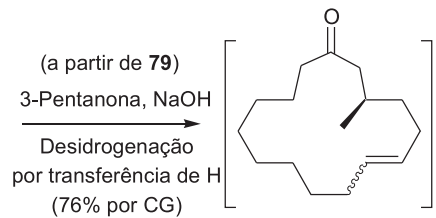

$\mathrm{X}=\mathrm{H}, \mathrm{OH}: 74 \%$ conversão por $\mathrm{CG}$ $\mathrm{X}=\mathrm{O}$ :conversão não mencionada

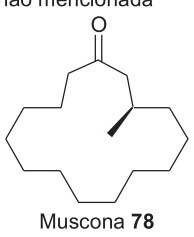

$56 \%$ a partir de 79 $75 \%$ a partir de $76 a$

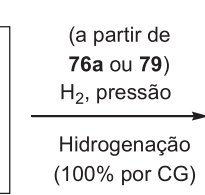

Esquema 23. Síntese de (R)-(-)-muscona por Grubbs e colaboradores ${ }^{(69)}$

\section{Antibiótico (-)-A26771B}

Uma estratégia de RCM-hidrogenação foi adotada por Chang e colaboradores na síntese formal do antibiótico macrocíclico de 16 membros (-)-A26771B 83, isolado de Penicillium turbatum (Esquema 24$)^{70}$. Neste trabalho, o uso de catalisador de Grubbs-I 3 conduziu à macrociclização do dieno terminal $\mathbf{8 0} \mathrm{em}$ bom rendimento e excelente estereosseletividade, não sendo observada reação competitiva com a ligação dupla $\mathrm{C} 2-\mathrm{C} 3$, devido à baixa afinidade do catalisador com esta ligação deficiente em elétrons. A redução seletiva da ligação dupla C9-C10 de $\mathbf{8 1}$ produziu o intermediário 82, cuja transformação em $\mathbf{8 3}$ estava já descrita na literatura ${ }^{71}$.

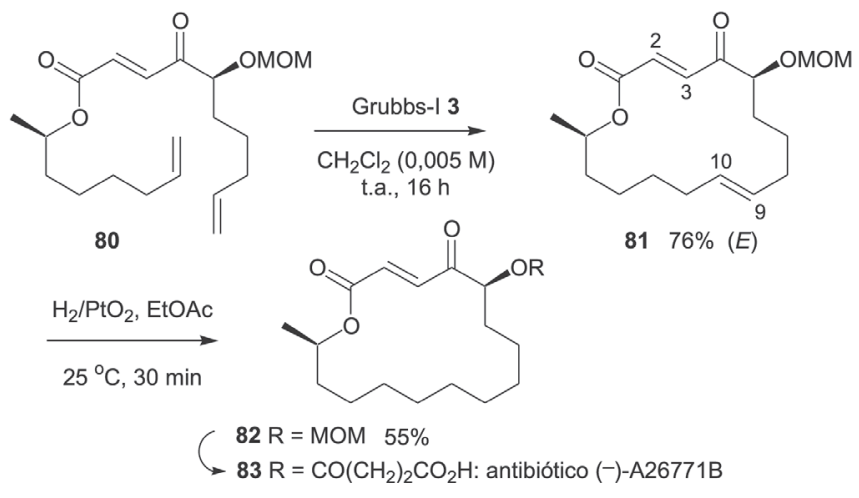

Esquema 24. Síntese formal do antibiótico (-)-A26771B

\section{Saraina A}

O alcalóide marinho saraina A $\mathbf{8 4}$ possui um sistema pentacíclico, incluindo um anel azacicloalcano saturado de 13 membros. Weinreb e colaboradores estudaram várias permutações possíveis de fechamento deste anel usando a estratégia de RCM, a

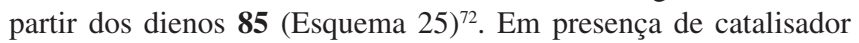
de Grubbs-I 3, observou-se que os substratos com $n=3$ ou 4 forneceram o produto desejado com rendimentos somente razoáveis (provavelmente devido à tensão estrutural dos produtos tricíclicos 86), juntamente com a produção colateral de grandes quantidades dos dímeros. O dieno $\mathbf{8 5}(\mathrm{n}=1)$ não reagiu, o que, neste caso, mostrou o papel desfavorável da proximidade de uma das ligações duplas ao sistema bicíclico inicial que impediu o desenvolvimento da reação. A hidrogenação direta da mistura de diastereoisômeros $E / Z$ $\mathbf{8 6}(\mathrm{n}=3)$ forneceu o intermediário chave $\mathbf{8 7}$, necessário para fina- lizar a síntese da saraina A. Recentemente, a reação de RCM correspondente a $n=3$ foi usada pelo mesmo grupo para preparar intermediários tetracíclicos avançados da saraina A. As reações foram conduzidas com o catalisador de Grubbs-II 5, gerando os produtos cíclicos de interesse com bons rendimentos e sem a presença de polímeros ${ }^{73}$. Finalmente, a primeira síntese total deste alcalóide complexo foi publicada em 2006 por Overman e colaboradores, usando a mesma estratégia $(\mathrm{n}=3)$ para fechar o macrociclo saturado da saraina $\mathrm{A}^{74}$.
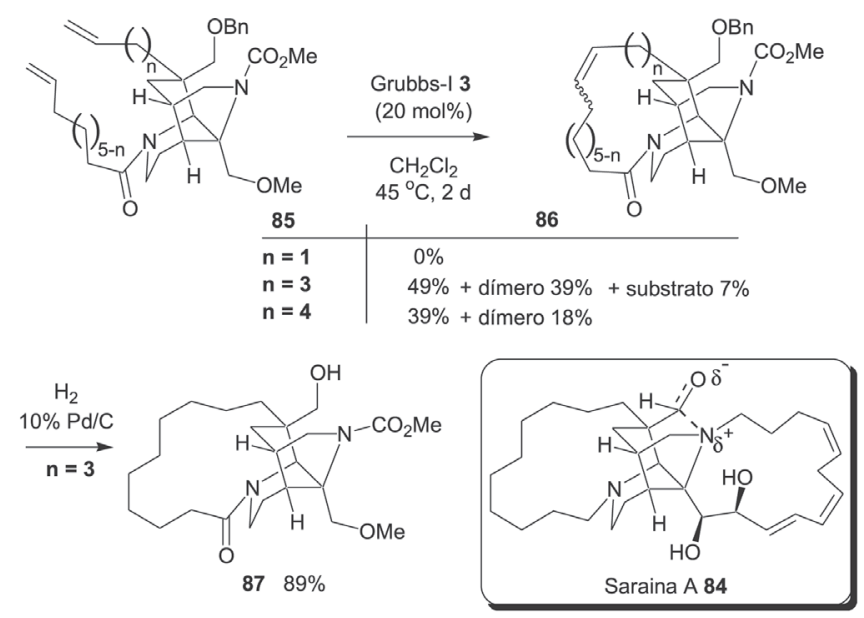

Esquema 25. Síntese de intermediários da síntese da saraina A

Os exemplos anteriores demonstram que o catalisador de Schrock 1, bem como os catalisadores de Grubbs-I $\mathbf{2}$ e $\mathbf{3}$ apresentam aplicações complementares. Já os catalisadores de rutênio Grubbs-II 4 e $\mathbf{5}$ de $2^{\mathrm{a}}$ geração surgem nos últimos anos, principalmente o catalisador $\mathbf{5}$, como ferramenta de uso mais abrangente, sendo capaz de atuar praticamente em todos os casos, particularmente na formação de cicloalcenos tetra-substituídos, na metátese de acrilatos ou de substratos pobres em elétrons, além de dienos com configuração restrita.

\section{Zearalenona}

Fürstner e colaboradores, dentre os primeiros, estudaram a reação de RCM no fechamento de macrociclos naturais comparando a utilização de catalisadores de primeira e de segunda geração, e efetuando estudos comparativos com outros métodos de ciclização, tais como a reação de McMurry, a reação de Stille e a reação de Heck $^{75}$. No caso da síntese do macrolido de 14 membros (S)-(-)zearalenona 90, a ciclização foi realizada ao nível da ligação dupla pouca reativa do sistema estirênico presente no precursor 88 (Esquema 26). Apenas o catalisador de rutênio de $2^{\text {a }}$ geração $\mathbf{4}$, pouco

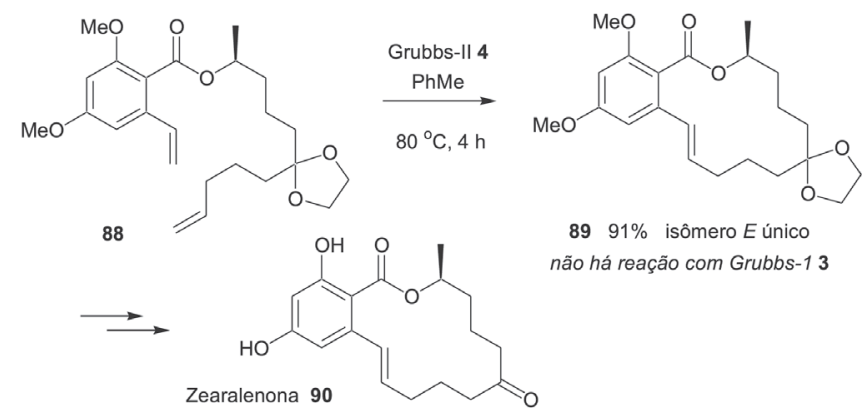

Esquema 26. Síntese de (S)-(-)-zearalenona via RCM 
utilizado em metátese de olefinas, forneceu a macrolactona desejada 89 de configuração $E$ em excelente rendimento.

\section{Migrastatina}

Na síntese da unidade cíclica central da macrolactona de 14 membros migrastatina 94, Gaul e Danishefsky obtiveram a lactona 92a de configuração $E$ em presença do catalisador de Grubbs-II 5, com rendimento de $50 \%$ (Esquema 27) ${ }^{76}$. Novamente, o catalisador de Grubbs-I 3 não foi eficiente, resultando na formação do dímero 93 a partir de 92a. Além da necessidade do uso do catalisador $\mathbf{5}$ mais reativo, as condições de temperatura utilizadas também foram mais drásticas que o usual (tolueno sob refluxo), provavelmente devido aos numerosos substituintes presentes na vizinhança da ligação dupla em C-7. Pouco depois, esta metodologia foi aplicada à síntese total da migrastatina 94, no entanto, produziu o intermediário cíclico 92b $E$ com $70 \%$ de rendimento ${ }^{77}$.

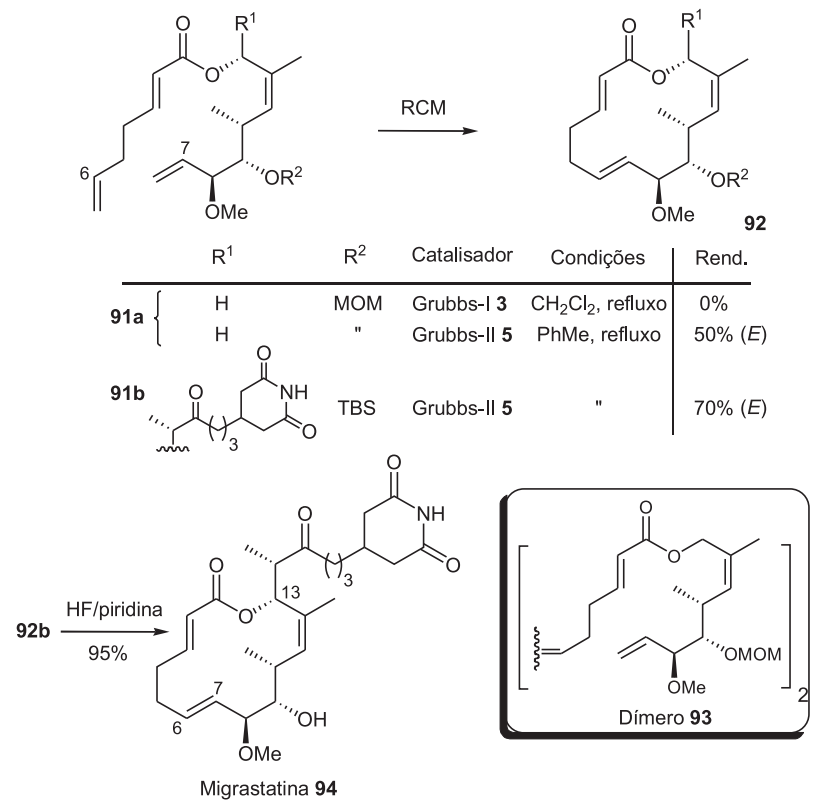

Esquema 27. Fechamento do anel macrocíclico da migrastanina via RCM

\section{Dactilolida/zampanolida}

Vários métodos de síntese do macrolido citotóxico poli-insaturado (-)-dactilolido 97, aparentemente o enantiômero do metabólito natural (+)-dactilolido e, também, do seu congênere estrutural, o (-)zampanolido 98 (ambos de origem marinha), envolvem como etapa chave de fechamento do anel a reação de RCM entre os carbonos C8 e $\mathrm{C} 9^{78}$. A primeira destas sínteses usa como precursor uma mistura dos álcoois alílicos epíméricos $\mathbf{9 5}$, em uma etapa “one pot”, sendo diretamente adicionado o catalisador de Grubbs-II 5 ao meio reacional de sililação das duas hidroxilas livres, em C19 e C20, para fornecer o macrociclo 96 em $77 \%$ de rendimento (Esquema 28). Este processo mostra a versatilidade da reação de RCM com o catalisador 5 e a tolerância a diversos grupos funcionais.

\section{Monocilina I, radicicol e cicloproparadicicol}

A tolerância da reação de RCM, no que diz respeito à diversidade de grupos funcionais, é ilustrada pela síntese dos macrolidos de 14 membros monocilina I $\mathbf{1 0 1}$ e radicicol 102, relatada por

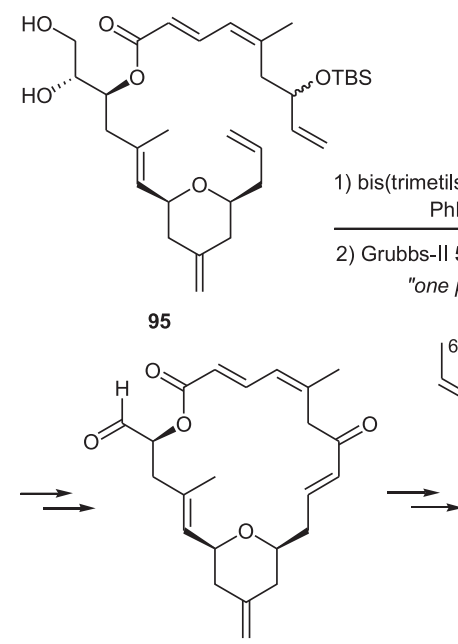

(-)-Dactilolido 97

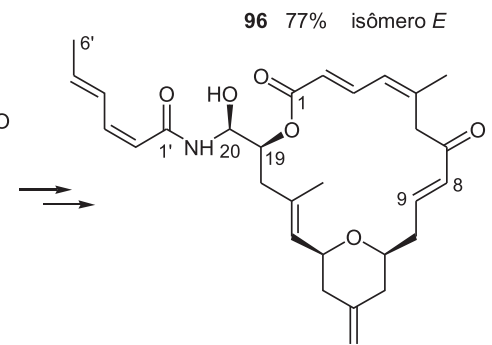

(-)-Zampanolido 98
Esquema 28. Síntese da (-)-dactilolido e da (-)-zampanolido via RCM

Danishefsky e colaboradores ${ }^{79}$. Em presença do catalisador de Grubbs-II 5, a ciclização dos substratos diênicos 99, contendo um epóxido alílico e uma função cetona protegida sob a forma de tioacetal, ocorreu com rendimentos de 55-60\% gerando os dienos macrocíclicos intermediários $\mathbf{1 0 0}$ de configuração $6 E, 8 Z$ (Esquema 29). A ausência de proteção das hidroxilas fenólicas conduziu a uma reação de RCM menos eficiente. Dificuldades de desmetilação das hidroxilas fenólicas na continuação da síntese obrigaram os autores a utilizar o intermediário sililado 100b, que foi transformado em monocilina I 101. Uma reação de cloração regiosseletiva subseqüente $\left(\mathrm{SO}_{2} \mathrm{Cl}_{2}\right.$ em $\left.\mathrm{Et}_{2} \mathrm{O}, 58 \%\right)$, forneceu o radicicol $\mathbf{1 0 2}$.
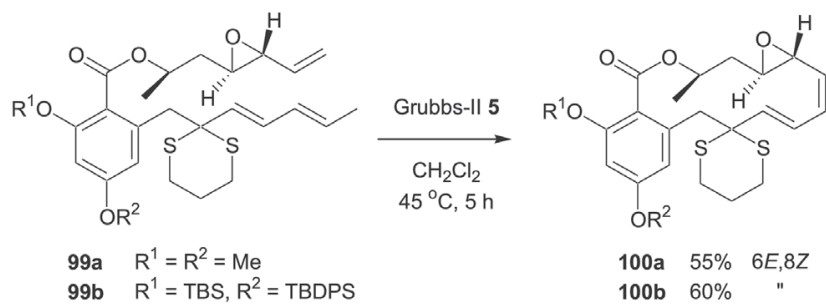

$\underset{60 \%}{\longrightarrow}$

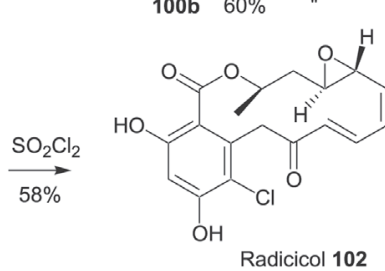

Esquema 29. Síntese da monocilina I e do radicicol via RCM

A fim de otimizar as propriedades antitumorais do radicicol, particularmente in vivo, Yang e Danishefsky sintetizaram análogos estruturais onde a função epóxido é substituída por um ciclopropano

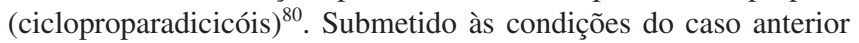
(Grubbs-II 5, $\mathrm{CH}_{2} \mathrm{Cl}_{2}$, refluxo, 19 h), o ciclo-propiltrieno 103 só conduziu, em $16 \%$ de rendimento, o macrolido esperado 104, acompanhado de $30 \%$ do macrociclo dimérico correspondente de 28 membros (Esquema 30). Após numerosos ensaios, as melhores condições testadas (tolueno, $110{ }^{\circ} \mathrm{C}, 10 \mathrm{~min}$ ) permitiram um rendimento de $55 \%$. Como comentado anteriormente, o balanceamento entre fatores termodinâmicos e cinéticos parece decisivo para o curso desta reação. O fato da razão dos produtos estar a favor do 
monômero, à temperatura elevada, indica que esta forma é favorecida entropicamente ${ }^{35}$.<smiles>C=CC(C)CCC1Cc2cc(O[18OH])cc(OC(C)(C)C)c2C(=O)OC1(/C=C/C=C/C)CC</smiles>

103
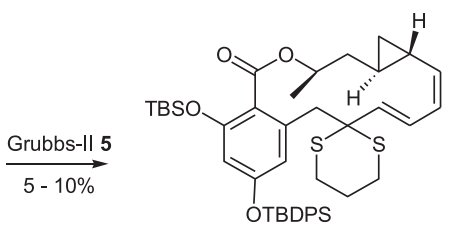

104

\begin{tabular}{|c|c|c|c|c|}
\hline \multicolumn{3}{|c|}{1} & \multicolumn{2}{|c|}{ Rend. } \\
\hline \multicolumn{3}{|c|}{ Condições } & 104 & Dímero \\
\hline $\mathrm{CH}_{2} \mathrm{Cl}_{2}$ & $42^{\circ} \mathrm{C}$ & $19 \mathrm{~h}$ & $16 \%$ & $30 \%$ \\
\hline $\mathrm{PhMe}$ & $42^{\circ} \mathrm{C}$ & $19 \mathrm{~h}$ & $27 \%$ & $48 \%$ \\
\hline $\mathrm{PhMe}$ & $110^{\circ} \mathrm{C}$ & $10 \mathrm{~min}$ & $55 \%$ & - \\
\hline
\end{tabular}

Esquema 30. Influência das condições sobre o fechamento do cicloproparadiciol

\section{Estratégia "inolido"; aigialomicina D}

Com vista ao aumento de escala na preparação de análogos do radicicol, este mesmo grupo de pesquisa desenvolveu uma estratégia alternativa chamada "inolido", usando um intermediário onde o núcleo aromático é formado após a formação da macrolactona, a partir de uma ligação tripla protegida de maneira intermediária na forma de complexo de cobalto cuja conformação angular $\left(140^{\circ}\right)$ favorece a reação de $\mathrm{RCM}^{81}$. Nesta abordagem, o núcleo aromático é gerado após o fechamento do macrociclo por reação de DielsAlder com um dieno adequado.

Além da aplicação na síntese de cicloproparadicicóis, esta estratégia de "inolido" foi aplicada com sucesso à síntese do macrolido aigialomicina D 107, inicialmente isolado de um fungo marinho de manguezal e dotada de atividades antimalárica e antitumoral ${ }^{82}$. Neste caso, o intermediário chave da estratégia "inolido" foi o complexo de cobalto 105 (Esquema 31). A ciclização ocorreu em presença do catalisador de Grubbs-II 5, fornecendo a macrolactona de interesse em rendimento de $80 \%$ e configuração $E$ exclusiva da ligação dupla C7'-C8'. Winssinger e colaboradores publicaram recentemente uma rota de síntese da aigialomicina D usando uma reação de RCM a partir de precursores 106, já incorporando o núcleo ressorcilato protegido com grupos éteres ${ }^{83}$. Estes autores desenvolveram também uma metodologia modular de síntese de análogos de 107 usando dienos ligados a polímeros e conduzindo a reação de RCM em forno de microondas a $120{ }^{\circ} \mathrm{C}$ em diclorometano.

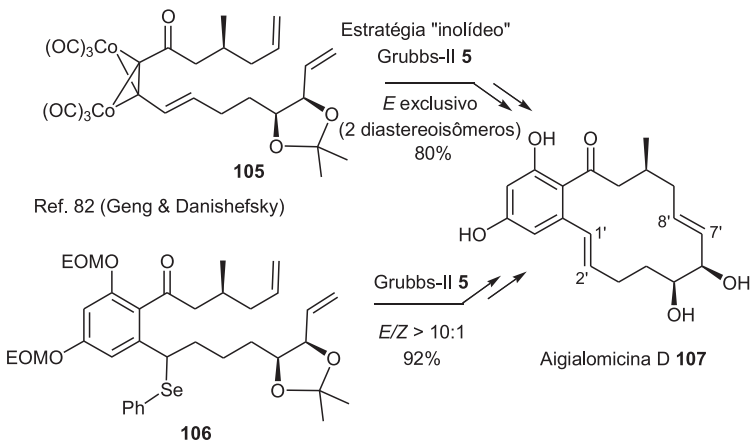

Ref.83 (Winssinger e cols.)

Esquema 31. Síntese da aigialomicina D

\section{Coleofomonas}

Nicolaou e colaboradores publicaram a síntese de diterpenos policíclicos da família das coleofomonas, produtos naturais antifúngicos com propriedades anti-hipertensivas promissoras, onde foi utilizada no fechamento do anel macrocíclico tensionado de 11 membros uma reação de RCM entre uma olefina terminal gem-disubstituída e uma olefina tri-substituída (Esquema 32) ${ }^{84}$. Como o uso direto do substrato tricarbonilado $\mathbf{1 0 8}$ resultou em baixos rendimentos na etapa de RCM, os mono-enol éteres correspondentes foram preparados em presença de diazometano, fornecendo uma mistura dos enol éteres regioisômeros 109a e 109b, que foram separados por cromatografia. Inexplicavelmente, a submissão desses isômeros às condições de RCM forneceu, respectivamente, as olefinas cíclicas Z-110a e $E$-110b. Estes intermediários foram posteriormente transformados em coleofomonas C 111a e B 111b.

Em um trabalho complementar ${ }^{85}$, foi observado que a substituição no $\mathrm{C} 1$ do anel aromático é o fator responsável pela seletividade $E$ da ciclização de $\mathbf{1 0 9}$ b. Na ausência de substituição nesta posição, um seco-éster análogo a 109b forneceu, como no caso de 109a, o isômero cíclico correspondente de configuração $Z$ (o mais estável termodinamicamente). O impedimento estéreo entre o substituinte na posição $\mathrm{C} 1$ e a metoxila vinílica vizinha força o anel aromático a ocupar uma posição ortogonal à ligação dupla C7-C8, promovendo a formação cinética do macrociclo $E-\mathbf{1 1 0 b}$. Este exemplo ilustra a dificuldade de antecipar o curso da reação de ciclização nos casos mais complexos.

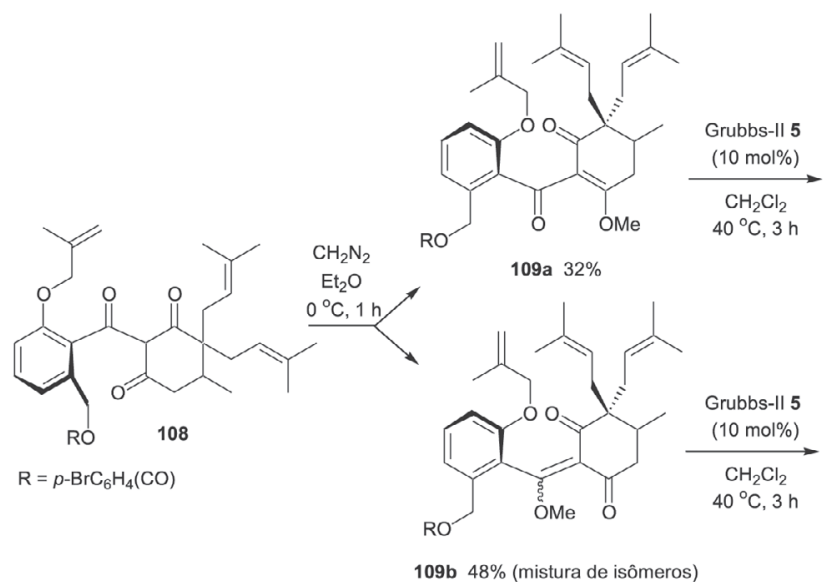

109b $48 \%$ (mistura de isômeros)
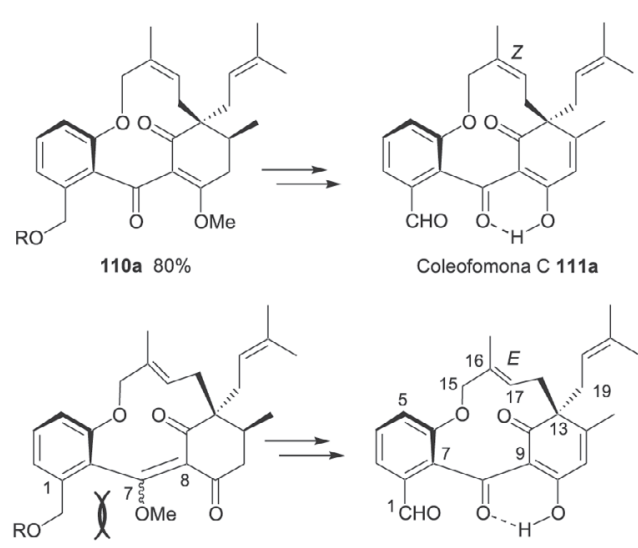

$110 \mathrm{~b} 86 \%$

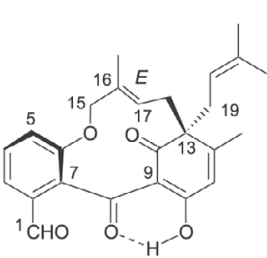

Coleofomona B 111b 


\section{Quendomicina}

A síntese do antibiótico policetídeo ansa (-)-quendomicina 115, isolado de Streptomyces violaceoruber, foi descrita por Smith e colaboradores, utilizando uma reação de RCM na formação do intermediário macrocíclico de 16 membros 113 (Esquema 33) ${ }^{86}$. As primeiras tentativas, realizadas a partir da cetona correspondente ao produto de oxidação da hidroxila em C19 de 112, utilizando o catalisador de Grubbs-II 5, não conduziram ao produto cíclico desejado. Subseqüentemente, a mistura 2:1 dos álcoois epímeros 19(S)-112/19(R)112 foi submetida às condições de RCM, conduzindo ao isômero macrocíclico único $19(S)$-113 que apresenta configuração $Z$ da ligação dupla formada, diferente da configuração do produto natural. Um fator decisivo para a resolução cinética observada pode vir da existência de uma ligação hidrogênio entre a hidroxila $19(S)$ e o grupo metoxila do anel aromático vizinho, o que induz uma orientação favorável das duas cadeias etilênicas. A presença dos grupos de proteção TBS mostrou-se igualmente necessária para o andamento da reação, também por razões conformacionais. A obtenção da ligação dupla tri-substituída de configuração $Z$ apareceu como o ponto fraco da síntese, exigindo um processo multi-etapas de isomerização da ligação dupla (intermediário 114). Estes resultados mostram, mais uma vez, que a reação de RCM é uma ferramenta eficiente na construção de moléculas macrocíclicas complexas, sendo a principal limitação a dificuldade da previsão da estereoquímica. Apesar de tudo, a síntese da (-)-quendomicina 115 representa uma das primeiras aplicações de uma reação de RCM na formação de um macrociclo complexo a 16 membros contendo uma ligação tri-substituída impedida.

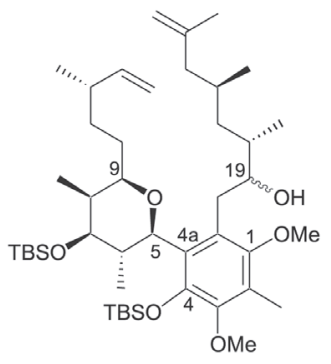

$19(S)-112 / 19(R)-112=2: 1$

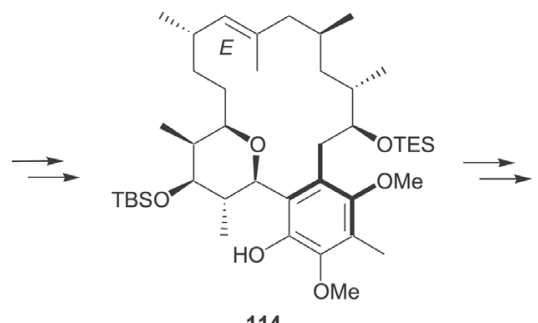

114

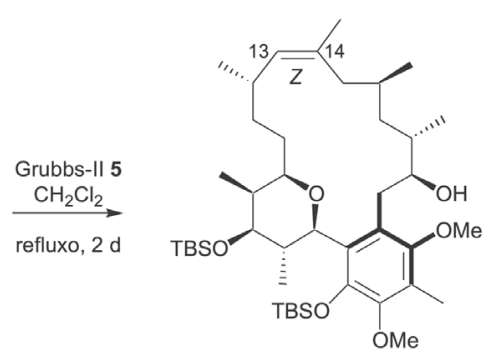

$11357 \%(13-Z, 19-S)$

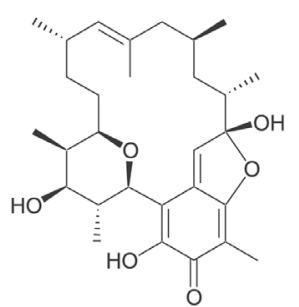

(-)-Quendomicina 115
Esquema 33. RCM aplicada à síntese de (-)-quendomicina

\section{CONCLUSÃO}

Atualmente, a reação de RCM já faz parte das ferramentas indispensáveis na síntese de macrociclos orgânicos. Devido a sua versatilidade, alta tolerância funcional e facilidade de execução, esta reação se tornou, em menos de 10 anos, o método de escolha na formação dos macrociclos naturais mais complexos comportando diversas funções orgânicas, numerosos centros assimétricos e igualmente outras partes cíclicas, fusionadas ou não. A reação é aplicada na formação da ligação dupla tanto como parte do produto final, quanto como grupo funcional intermediário, posteriormente transformada em outras funções alvo, o que amplia o espectro de utilização da metodologia. Nota-se que os catalisadores de molibdênio e de rutênio de primeira geração (Grubbs-I) apresentam atividades complementares, sendo utilizados em vários trabalhos de síntese. Entretanto, a capacidade dos catalisadores de rutênio de segunda geração (Grubbs-II) de manter atividade tão boa quanto a do catalisador de molibdênio de Schrock 1, juntamente com a estabilidade dos catalisadores de Grubbs-I, faz com que estes sejam as opções de escolha para grande parte das aplicações mais avançadas. Entre as principais limitações, além do custo elevado dos catalisadores, destacam-se as dificuldades na previsão da reatividade dos dienos precursores e no controle da configuração da ligação dupla formada. Este último ponto representa uma dificuldade específica na formação de macrociclos, em comparação com a formação de pequenos anéis. Além disso, a aplicação da reação de metátese na síntese de compostos macrocíclicos tensionados pode mostrar-se particularmente delicada e, até mesmo conduzir a impasses, como no caso da pondaplina (uma ansa-macrolactona tensa de $13 \mathrm{mem}$ bros isolada de folhas de Annona glabra). As tentativas de RCM para fechar o sistema [9]-paraciclofano desta molécula por Bressy e Piva $^{87}$, assim como as de Yadav e colaboradores ${ }^{88}$, falharam.

Contudo, o acúmulo dos exemplos de sucessos e, eventualmente, os de fracassos, permite hoje uma melhor previsão dos fatores determinantes para o bom andamento das reações de macro-ciclização. Como conseqüência, permite também antecipar os resultados com melhor probabilidade de acerto. Com certeza, uma das maiores perspectivas nesta área está no desenvolvimento de catalisadores de menor custo e que garantam um maior controle das características dos produtos formados, favorecendo futuramente o uso desta ferramenta em processos industriais.

\section{REFERÊNCIAS}

1. Para algumas revisões, ver: Astruc, D.; New. J. Chem. 2005, 29, 42; Nicolaou, K. C.; Bulger, P. G.; Sarlah, D.; Angew. Chem., Int. Ed. 2005, 44, 4490; Trnka, T. M.; Grubbs, R. H.; Acc. Chem. Res. 2001, 34, 18; Para uma revisão detalhada sobre a metátese, ver: Handbook of Metathesis; Grubbs, R. H., ed.; Wiley-VCH: Weinheim, 2003.

2. Frederico, D.; Brocksom, U.; Brocksom, T. J.; Quim. Nova 2005, $28,692$.

3. Matos, J. M. E.; Batista, N. C.; Carvalho, R. M.; Santana, S. A. A.; Puzzi, P. N.; Sanches, M.; Lima-Neto, B. S.; Quim. Nova 2007, 30, 431.

4. Gradillas, A.; Pérez-Castells, J.; Angew. Chem., Int. Ed. 2006, 45, 6086; van de Weghe, P.; Eustache, J.; Curr. Top. Med. Chem. 2005, 5, 1495; Prunet, J.; Angew. Chem., Int. Ed. 2003, 42, 2826.

5. Newman, D. J.; Cragg, G. M.; Snader, K. M.; J. Nat. Prod. 2003, 66, 1022.

6. Balunas, M. J.; Kinghorn, D.; Life Sci. 2005, 78, 431; Butler, M. S.; J. Nat. Prod. 2004, 67, 2141; Shu, Y.-Z.; J. Nat. Prod. 1998, 61, 1053.

7. Wessjohann, L. A.; Ruijter, E.; Garcia-Rivera, D.; Brandt, W.; Mol. Diversity 2005, 9, 171.

8. Höfle, G.; Bedorf, N.; Steinmetz, H.; Schomburg, D.; Gerth, K.; Reichenbach, H.; Angew. Chem., Int. Ed. 1996, 35, 1567.

9. Pettit, G. R.; Herald, C. L.; Doubek, D. L.; Herald, D. L.; Arnold, E.; Clardy, J.; J. Am. Chem. Soc. 1982, 104, 6846.

10. Kim, J. W.; Adachi, H.; ShinYa, K.; Hayakawa, Y.; Seto, H.; J. Antibiot. 1997, 50, 628; Hayakawa, Y.; Kim, J. W.; Adachi, H.; Shinya, K.; Fujita, K.; Seto, H.; J. Am. Chem. Soc. 1998, 120, 3524.

11. Crews, P.; Manes, L. V.; Boehler, M.; Tetrahedron Lett. 1986, 27, 2797; Zabriskie, T. M.; Klocke, J. A.; Ireland, C. M.; Marcus, A. H.; Molinski, T. F.; Faulkner, D. J.; Xu, C.; Clardy, J. C.; J. Am. Chem. Soc. 1986, 108, 3123; Zampella, A.; Giannini, C.; Debitus, C.; Roussakis, C.; D’Auria, M. V. ; J. Nat. Prod. 1999, 62, 332.

12. Marrero, J.; Rodriguez, A. D.; Baran, P.; Raptis, R. G.; Eur. J. Org. Chem. 2004, 3909.

13. Revisão sobre macrolidos marinhos: Paterson, I.; Kap-Sun Yeung, K.-S.; Chem. Rev. 2005, 105, 4237; Macrodiolídeos: Kang, E.-J.; Lee, E.; Chem. Rev. 2005, 105, 4348; Macrociclos poliênicos: Rychnovsky, S. D.; Chem. Rev. 1995, 95, 2021.

14. Inanaga, J.; Hirata, K.; Saeki, H.; Katsuki, T.; Yamaguchi, M.; Bull. Chem. Soc. Jpn. 1979, 52, 1989. 
15. Exemplos de macrociclização via protocolo de Yamaguchi, ver: Jin, M.; Taylor, R. E.; Org. Lett. 2005, 7, 1303; Kumar, P.; Naidu, S. V.; J. Org. Chem. 2005, 70, 4207; Wipf, P.; Graham, T. H.; J. Am. Chem. Soc. 2004, 126, 15346; Sharma, G. V. M.; Reddy, Ch. G.; Tetrahedron Lett. 2004, 45, 7483; Williams, D. R.; Patnaik, S.; Plummer, S. V.; Org. Lett. 2003, 5, 5035.

16. Neises, B.; Steglich, W.; Angew. Chem., Int. Ed. 1978, 17, 522; Boden, E. P.; Keck, G. E.; J. Org. Chem. 1985, 50, 2394.

17. Exemplos de macrociclização via reação de Steglich, ver: Ferrié, L.; Capdevielle, P.; Cossy, J.; Synlett 2005, 1933; White, J. D.; Amedio, J. C. Jr.; J. Org. Chem. 1989, 54, 736.

18. Mitsunobu, O.; Synthesis 1981, 1; Hughes, D. L.; Reamer, R. A.; Bergan, J. J.; Grabowski, E. J. J.; J. Am. Chem. Soc. 1988, 110, 6487

19. Exemplos de macrociclização pelo protocolo de Mitsunobu, ver: Chen, Y; Gambs, C.; Abe, Y.; Wentworth, P. Jr.; Janda, K. D.; J. Org. Chem. 2003, 68, 8902; Shen, R.; Lin, C. T.; Porco, J. A. Jr.; J. Am. Chem. Soc. 2002, 124, 5650; Paterson, I.; De Savi, C.; Tudge, M.; Org. Lett. 2001, 3, 213; Feutrill, J. T.; Holloway, G. A.; Hilli, F.; Hügel, H. M.; Rizzacasa, M. A.; Tetrahedron Lett. 2000, 41, 8569.

20. Exemplos de macrolactamização, ver: Tanaka, H.; Sawayama, A. M.; Wandless, T. J.; J Am. Chem. Soc. 2003, 125, 6864; Matsushima, Y.; Itoh, H.; Nakayama, T.; Horiuchi, S.; Eguchi, T.; Kakinuma, K.; J. Chem. Soc., Perkin Trans. 1 2002, 949; Yokokawa, F.; Sameshima, H.; Katagiri, D.; Aoyama, T.; Shioiri, T.; Tetrahedron 2002, 58, 9445; Boisnard, S.; Carbonnelle, A.-C.; Zhu, J.; Org. Lett. 2001, 3, 2061.

21. Exemplos de macrociclização por reação de Horner-Emmons, ver: Smith III, A. B.; Safonov, I. G.; Org. Lett. 2002, 4, 635; Smith III, A. B.; Safonov, I. G.; Corbett, R. M.; J. Am. Chem. Soc. 2001, 123, 12426; Keck, G. E.; Wager, C. A.; Wager, T. T.; Savin, K. A. Covel, J. A.; McLaws, M. D.; Krishnamurthy, D. Cee, V. G.; Angew. Chem., Int. Ed. 2001, 40, 231.

22. Exemplos de macrociclização por acoplamento de Stille, ver: Garg, N. K.; Hiebert, S.; Overman, L.; Angew. Chem., Int. Ed. 2006, 45, 2912; Quéron, E.; Lett, R.; Tetrahedron Lett. 2004, 45, 4539; Mitchell, I. S.; Pattenden, G.; Stonehouse, J. P.; Tetrahedron Lett. 2002, 43, 493; Pequena revisão: Pattenden, G.; Sinclair, D. J.; J. Organomet. Chem. 2002, 653, 261.

23. Exemplos de macrociclização por reação de Suzuki-Miyaura, ver: Kallan, N. C.; Halcomb, R. L.; Org. Lett. 2000, 2, 2687; Chemier, S. R.; Danishefsky, S. D.; Org. Lett. 2000, 2, 2695.

24. Exemplo de macrociclização por reação de McMurry, ver: Liu, Z.; Li, W. Z.; Li, Y.; Tetrahedron: Asymmetry 2001, 12, 995.

25. Histórico do desenvolvimento da metátese, ver: Baibich, I. M.; Gregório, J. R.; Quim. Nova 1993, 16, 120.

26. Hérisson, J.-L.; Chauvin, Y.; Macromol. Chem. 1971, 141, 161

27. Schrock, R. R.; Murdzek, J. S.; Bazan, G. C.; Robbins, J. R.; DiMare, M.; O'Regan, M.; J. Am. Chem. Soc. 1990, 112, 3875; Para uma revisão, ver: Schrock, R. R.; Hoveyda, A. H.; Angew. Chem., Int. Ed. 2003, 42, 4592.

28. Para revisão, ver: Grubbs, R. H.; Tetrahedron 2004, 60, 7117.

29. Kirkland, T. A.; Grubbs, R. H.; J. Org. Chem. 1997, 62, 7310.

30. Nguyen, S. T.; Grubbs, R. H.; J. Am. Chem. Soc. 1993, 115, 9858.

31 Schwab, P.; France, M. B.; Ziller, J. W.; Grubbs, R. H.; Angew. Chem., Int. Ed. 1995, 34, 2039.

32. Weskamp, T.; Schattenmann, W. C.; Spiegler, M.; Herrmann, W. A.; Angew. Chem., Int. Ed. 1998, 37, 2490; Scholl, M.; Trnka, T. M.; Morgan, J. P.; Grubbs, R. H.; Tetrahedron Lett. 1999, 40, 2247; Scholl, M.; Ding, S.; Lee, C. W.; Grubbs, R. H.; Org. Lett. 1999, 1, 953; Jafarpour, L.; Hillier, A. C.; Nolan, S. P.; Organometallics 2002, 21, 442; Guerra, J.; Synlett 2003, 423.

33. Exemplo de uso de catalisador de Grubbs-I 3 na formação de ligações duplas tri-substituídas, ver: Srikrishna, A.; Dethe, D. H.; Tetrahedron Lett. 2003, 44, 7817 .

34. Deiters, A.; Martin, S. F.; Chem. Rev. 2004, 104, 2199; Grubbs, R. H.; Chang, S.; Tetrahedron 1998, 54, 4413

35. Xu, Z.; Johannes, C. W.; Salman, S. S.; Hoveyda, A. H.; J. Am. Chem. Soc. 1996, 118, 10926.

36. Yamamoto, K.; Biswas, K.; Gaul, C.; Danishefsky, S. J.; Tetrahedron Lett. 2003, 44, 3297; Biswas, K.; Lin, H.; Njardarson, J. T.; Chappell, M. D.; Chou, T. C.; Guan, Y.; Tong, W. P.; He, L.; Horwitz, S. B.; Danishefsky, S. J.; J. Am. Chem. Soc. 2002, 124, 9825.

37. Fürstner, A.; Langemann, K.; Synthesis 1997, 792.

38. Goldring, W. P. D.; Hodder, A. S.; Weiler, L.; Tetrahedron Lett. 1998, 39, 4955.

39. Fürstner, A.; Langemann, K.; J. Am. Chem. Soc. 1997, 119, 9130.

40. Eh, M.; Synthesis 2003, 365.

41. Baltrusch, A. W.; Bracher, F.; Synlett 2002, 1724

42. Evano, G.; Schaus, J. V.; Panek, J. S.; Org. Lett. 2004, 6, 525.

43. Sello, J. K.; Andreana, P. R.; Lee, D.; Schreiber, S. L.; Org. Lett. 2003, 5, 4125 .

44. Banwell, M. G.; McRae, K. J.; Org. Lett. 2000, 2, 3583

45. Dixon, D. J.; Foster, A. C.; Ley, S. V.; Org. Lett. 2000, 2, 123.
46. Lee, C. W.; Grubbs, R. H.; Org. Lett. 2000, 2, 2145

47. Wu, Y.; Liao, X.; Wang, R.; Xie, X.-S.; De Brabander, J. K.; J. Am. Chem. Soc. 2002, 124, 3245.

48. Fürstner, A.; Radkowski, K.; Wirtz, C.; Goddard, R.; Lehmann, C. W.; Mynott, R.; J. Am. Chem. Soc. 2002, 124, 7061.

49. Garcia-Fortanet, J.; Murga, J.; Falomir, E.; Carda, M.; Marco, J. A.; J. Org. Chem. 2005, 70, 9822.

50. Jasper, C.; Wittenberg, R.; Quitschalle, M.; Jakupovic, J.; Kirschning, A.; Org. Lett. 2005, 7, 479.

51. Nicolaou, K. C.; He, Y.; Vourloumis, D.; Vallberg, H.; Roschangar, F.; Sarabia, F.; Ninkovic, S.; Yang, Z.; Trujillo, J. I.; J. Am. Chem. Soc. 1997, 119, 7960.

52. Meng, D.; Bertinato, P.; Balog, A.; Su, D.-S.; Kamenecka, T.; Sorensen, E. J.; Danishefsky, S. J.; J. Am. Chem. Soc. 1997, 119, 10073.

53. Para outras revisões sobre os trabalhos de síntese das epotilonas, ver: Nicolaou, K. C.; Roschangar, F.; Vourloumis, D.; Angew. Chem., Int. Ed. 1998, 37, 2014; Nicolaou, K. C.; Ritzèn, A.; Namato, K.; Chem. Commun. 2001, 1523 .

54. Meng, D.; Su, D.-S.; Balog, A.; Bertinato, P.; Sorensen, A. J.; Danishefsky, S. J.; Zheng, Y.-H.; Chou, T.-C.; He, L.; Horwitz, S. B.; J. Am. Chem. Soc. 1997, 119, 2733.

55. Sun, J.; Sinha, S. C.; Angew. Chem., Int. Ed. 2002, 41, 1381.

56. Fürstner, A.; Davies, P. W.; Chem. Commun. 2005, 2307.

57. Fürstner, A.; Mathes, C.; Grela, K.; Chem. Commun. 2001, 1057.

58. Beutler, J. A.; McKee, T. C.; Curr. Med. Chem. 2003, 10, 787.

59. Yet, L.; Chem. Rev. 2003, 103, 4283.

60. Herb, C.; Dettner, F.; Maier, M. E.; Eur. J. Org. Chem. 2005, 728.

61. Haack, T.; Haack, K. L.; Diederich, W. E.; Blackman, B.; Roy, S.; Pusuluri, S.; Georg, G. I.; J. Org. Chem. 2005, 70, 7592; Para efeitos semelhantes, ver também: Fürstner, A.; Thiel, O. R.; Blanda, G.; Org. Lett. 2000, 2, 3731; Fürstner, A.; Dierkes, T.; Thiel, O. R.; Blanda, G.; Chem. Eur. J. 2001, 7, 5286.

62. Para uma pequena revisão, ver: Wallace, D. J.; Angew. Chem., Int. Ed. 2005, 44, 1912.

63. Wang, X.; Porco, A. Jr; J. Am. Chem. Soc. 2003, 125, 6040.

64. Wang, X.; Bowman, E. J.; Bowman, B. J.; Porco, A. Jr; Angew. Chem., Int. Ed. 2004, 43, 3601.

65. Content, S.; Dutton, C. J.; Roberts, L.; Bioorg. Med. Chem. Lett. 2003 , 13,321 .

66. Lemarchand, A.; Bach, T.; Tetrahedron 2004, 60, 9659.

67. Bach, T.; Lemarchand, A.; Synlett 2002, 1302.

68. Kamat, V. P.; Hagiwara, H.; Suzuki, T.; Ando, M.; J. Chem. Soc., Perkin Trans. 1 1998, 2253; Kamat, V. P.; Hagiwara, H.; Katsumi, T.; Hoshi, T.; Suzuki, T.; Ando, M.; Tetrahedron 2000, 56, 4397.

69. Louie, J.; Bielawski, C. W.; Grubbs, R. H.; J. Am. Chem. Soc. 2001, 123, 11312.

70. Lee, W.-W.; Shin, H. J.; Chang, S.; Tetrahedron: Asymmetry 2001, 12, 29.

71. Kobayashi, Y.; Okui, H.; J. Org. Chem. 2000, 65, 612

72. Irie, O.; Samizu, K.; Henry, J. R.; Weinreb, S. M.; J. Org. Chem. 1999, $64,587$.

73. Hong, S.; Yang, J.; Weinreb, S. M.; J. Org. Chem. 2006, 71, 2078.

74. Garg, N. K.; Hiebert, S.; Overman, L. E.; Angew. Chem., Int. Ed. 2006, 45, 2912.

75. Fürstner, A.; Thiel, O. R.; Kindler, N.; Bartkowska, B.; J. Org. Chem. 2000, 65, 7990.

76. Gaul, C.; Danishefsky, S. J.; Tetrahedron Lett. 2002, 43, 9039.

77. Gaul, G.; Njardarson, J. T.; Danishefsky, S. J.; J. Am. Chem. Soc. 2003 , 125,6042 .

78. Hoye, T. R.; Hu, M.; J. Am. Chem. Soc. 2003, 125, 9576; Ding, F.; Jennings M. P.; Org. Lett. 2005, 7, 2321; Louis, I.; Hungerford, N. L.; Humphries, E. J.; McLeod, M. D.; Org. Lett. 2006, 8, 1117.

79. Garbaccio, R. M.; Stachel, S. J.; Baeschlin, D. K.; Danishefsky, S. J.; J. Am. Chem. Soc. 2001, 123, 10903.

80. Para revisão, ver: Geng, X.; Yang, Z.-Q.; Danishefsky, S. J.; Synlett 2004, 1325.

81. Yang, Z.-Q.; Danishefsky, S. J.; J. Am. Chem. Soc. 2003, 125, 9602.

82. Geng, X. D.; Danishefsky, S. J.; Org. Lett. 2004, 6, 413.

83. Barluenga, S.; Dakas, P.-Y.; Ferandin, Y.; Meijer, L.; Winssinger, N.; Angew. Chem., Int. Ed. 2006, 45, 3951.

84. Nicolaou, K. C.; Vassilikogiannakis, G.; Montagnon, T.; Angew. Chem., Int. Ed. 2002, 41, 3276.

85. Vassilikogiannakis, G.; Margaros, I.; Tofi, M.; Org. Lett. 2004, 6, 205.

86. Smith III, A. B.; Mesaros, E. F.; Meyer, E. A.; J. Am. Chem. Soc. 2005 , 127, 6948; Smith III, A. B.; Mesaros, E. F.; Meyer, E. A.; J. Am. Chem. Soc. 2006, 128, 2192.

87. Bressy, C.; Piva, O.; Synlett 2003, 87.

88. Sabitha, G.; Swapna, R.; Satheesh Babu, R.; Yadav, J. S.; Tetrahedron Lett. $\mathbf{2 0 0 5}, 46,6145$. 